\title{
Intranasal rapamycin ameliorates Alzheimer- like cognitive decline in a mouse model of Down syndrome
}

\author{
Antonella Tramutola ${ }^{1 \dagger}$, Chiara Lanzillotta ${ }^{1 \dagger}$, Eugenio Barone ${ }^{1,2}$, Andrea Arena ${ }^{1}$, Ilaria Zuliani ${ }^{1}$, Luciana Mosca $^{1}$, \\ Carla Blarzino ${ }^{1}$, D. Allan Butterfield ${ }^{3}$, Marzia Perluigi ${ }^{1 *}$ and Fabio Di Domenico ${ }^{1 *}$ (D)
}

\begin{abstract}
Background: Down syndrome (DS) individuals, by the age of 40s, are at increased risk to develop Alzheimer-like dementia, with deposition in brain of senile plaques and neurofibrillary tangles. Our laboratory recently demonstrated the disturbance of PI3K/AKT/mTOR axis in DS brain, prior and after the development of Alzheimer Disease (AD). The aberrant modulation of the mTOR signalling in DS and AD age-related cognitive decline affects crucial neuronal pathways, including insulin signaling and autophagy, involved in pathology onset and progression. Within this context, the therapeutic use of mTOR-inhibitors may prevent/attenuate the neurodegenerative phenomena. By our work we aimed to rescue mTOR signalling in DS mice by a novel rapamycin intranasal administration protocol (InRapa) that maximizes brain delivery and reduce systemic side effects.
\end{abstract}

Methods: Ts65Dn mice were administered with InRapa for 12 weeks, starting at 6 months of age demonstrating, at the end of the treatment by radial arms maze and novel object recognition testing, rescued cognition.

Results: The analysis of mTOR signalling, after InRapa, demonstrated in Ts65Dn mice hippocampus the inhibition of mTOR (reduced to physiological levels), which led, through the rescue of autophagy and insulin signalling, to reduced APP levels, APP processing and APP metabolites production, as well as, to reduced tau hyperphosphorylation. In addition, a reduction of oxidative stress markers was also observed.

Discussion: These findings demonstrate that chronic InRapa administration is able to exert a neuroprotective effect on Ts65Dn hippocampus by reducing AD pathological hallmarks and by restoring protein homeostasis, thus ultimately resulting in improved cognition. Results are discussed in term of a potential novel targeted therapeutic approach to reduce cognitive decline and AD-like neuropathology in DS individuals.

Keywords: mTOR, Autophagy, Rapamycin, Down syndrome, Alzheimer disease, APP, Tau, Oxidative stress

\section{Background}

Down syndrome (DS) is the most common genetic cause of intellectual disability due to total or partial triplication of chromosome 21 (trisomy 21) [1]. The increased risk to develop Alzheimer-like dementia in DS individuals is becoming a key issue to manage the extension of the lifespan of DS population. Indeed, if from one side the improved quality of life and the longer life expectancy are significant

\footnotetext{
*Correspondence: marzia.perluigi@uniroma1.it;

fabio.didomenico@uniroma1.it

${ }^{+}$Antonella Tramutola and Chiara Lanzillotta contributed equally to this work. 'Department of Biochemical Sciences, Sapienza University of Rome, P.le Aldo Moro 5, 00185 Rome, Italy

Full list of author information is available at the end of the article
}

achievements of both social and medical care, the overall increase of mean age of DS individuals is associated with an elevated risk to develop age-associated disorders, among which Alzheimer disease (AD) [2]. The neuropathological conditions of DS subjects are complex and involve: deposition of senile plaques and neurofibrillary tangles, dysfunctional mitochondria, defective neurogenesis, increased oxidative stress and altered proteostasis [3]. Approximately two-thirds of individuals with DS develop dementia and brain pathological hallmarks in their 50s, but severity varies significantly among DS population [1]. The triplication of amyloid precursor protein (APP) is considered the major pathological event in both $\mathrm{AD}$ and

(C) The Author(s). 2018 Open Access This article is distributed under the terms of the Creative Commons Attribution 4.0 International License (http://creativecommons.org/licenses/by/4.0/), which permits unrestricted use, distribution, and 
DS with AD, but it is likely that several other triplicated genes contribute to the neurodegenerative process $[2,4-$ 6]. Our previous studies investigated the molecular mechanisms responsible for early onset of AD in DS, focusing attention on the mechanisms that lead to the impairment of protein quality control (PQC) pathways, including the ubiquitin proteasome system (UPS) and autophagy [7, 8]. We showed, in the frontal cortex from DS individuals before and after development of $\mathrm{AD}$ neuropathology, that key components of the PQC are irreversibly oxidatively modified resulting in aberrant protein functionality [7, 9]. In agreement, we observed, in young DS subjects, the early accumulation of polyubiquitinylated proteins before the appearance of AD symptoms $[10,11]$. These data suggest that impairment of protein degradative system may play a crucial role in the early accumulation of amyloid beta $(\mathrm{A} \beta)$ and tau toxic protein aggregates, thus accelerating the neurodegenerative process. Collecting studies suggest that, in AD brain and animal models thereof, the reduced autophagy is strongly associated with the hyperactivation of the PI3K/AKT/mTOR axis, leading to the accumulation of protein aggregates [12, 13]. In the central nervous system (CNS), mTOR and its downstream signalling pathways are involved in synaptic plasticity, memory retention, neuroendocrine regulation, puberty, and neuronal recovery [14-16]. Dysregulation of the mTOR pathway is emerging as a leitmotif in a large number of human diseases, including cancer, metabolic syndromes, and neurological disorders. In the last decade, great attention has been dedicated to the role of mTOR in the development of AD. mTOR hyperactivity is observed in $\mathrm{AD}$ brains from human and mouse models, and strong evidence demonstrated that alterations of mTOR may be one of the leading events contributing to the formation of toxic aggregates during AD pathology [17-20]. Recent studies from our laboratory and others employing specimens from DS individuals and DS mouse models confirmed that aberrant mTOR signalling is an early degenerating event in the brain that contributes to acceleration of $A \beta$ and tau deposition and to the development of AD-like cognitive decline [7, 9, 13, 21, 22]. In particular, we investigated the status of the PI3K/AKT/mTOR pathway in the frontal cortex from DS autopsy cases without AD neuropathology (typically under the age of 40 years) and DS with AD neuropathology [13]. Our results showed the hyperactivation of the PI3K/AKT/mTOR axis in the brains of subjects with DS with or without AD pathology in comparison to healthy individuals. These data were associated with decreased autophagosome formation and increased levels of $A \beta$ and $p$-tau.

These findings represent a strong rationale to test therapeutic strategies aimed to restore the functionality of PQC or prevent its gradual loss. Among drug candidates, mTOR inhibitors led to enormous interest as potential AD-modifying agents [20, 23-28], thus representing an appealing potential approach against neurodegeneration. Evidence showing the positive effects on memory of orally administered rapamycin demonstrated the concomitant reduction, of AD pathological markers, including $\mathrm{A} \beta$ and tau levels, in Tg mouse models of $\mathrm{AD}$ $[16,19,27,29-32]$. In the present work, we employed a novel therapeutic strategy using rapamycin, a selective inhibitor of mTOR, delivered by intranasal route in order to avoid peripheral accumulation. Our treatment supports the pathological role of aberrant mTOR/autophagy axis in DS mice and propose/confirm mTOR as a valuable target to prevent/slow the development of AD-related cognitive decline in DS as well as in the general population.

\section{Methods}

\section{Mouse colony}

Ts65Dn (B6EiC3Sn a/A-Ts(1716)65Dn/J), a well-established mouse model of DS, carries a reciprocal translocation that is trisomic for approximately 104 genes (56\%) on Mmu16, from Mrpl39 to the distal telomere, with homologues on HSA21. Mice were generated by repeatedly backcrossing Ts65Dn trisomic females with (B6EiC3SnF1/J) F1 hybrid males. The parental generations were purchased from Jackson Laboratories (Bar Harbour, ME, USA). These breeding pairs produce litters containing both trisomic (Ts65Dn) and euploid (Eu) offsprings. The pups were genotyped to determine trisomy using standard PCR, as described by Reinoldth [33]. In addition, the recessive retinal degeneration 1 mutation (Pdebrd1), which segregates in the colony and results in blindness in homozygotes, was analyzed for all trisomic animals used in the present study by standard PCR. Animals expressing the mutant gene were excluded from the behavioral studies. Mice were housed in clear Plexiglas cages $(20 \times 22 \times 20 \mathrm{~cm})$ under standard laboratory conditions with a temperature of $22 \pm 2{ }^{\circ} \mathrm{C}$ and $70 \%$ humidity, a 12-h light/dark cycle and free access to food and water. Littermates were spliced among age groups to avoid littermates/dam-specific effects. Mice characteristics are reported in Table 1. Mice were sacrificed by cervical dislocation. Trunk blood was collected from the site where the animal was decapitated. Animals were perfused with saline and one brain hemisphere was dissected for immunochemical analysis while the other brain hemisphere was fixed and collected for immunofluorescence staining. All the experiments were performed in strict compliance with the Italian National Laws (DL 116/92), the European Communities Council Directives (86/609/EEC). Experimental protocol was approved by Italian Ministry of Health authorization $\mathrm{n}^{\circ}$ 1183/2016-PR. All efforts were made to minimize the number of animals used in the study and their suffering. All samples were flash-frozen and stored at $-80{ }^{\circ} \mathrm{C}$ until utilization. 
Table 1 Mouse samples characteristics and experimental use

\begin{tabular}{|c|c|c|c|c|c|c|c|c|c|}
\hline \multirow[t]{2}{*}{ Treatment } & \multirow[t]{2}{*}{ Genotyping } & \multirow[t]{2}{*}{$\mathrm{n}$} & \multirow{2}{*}{$\begin{array}{l}\text { Gender } \\
(\mathrm{m} / \mathrm{f})\end{array}$} & \multirow{2}{*}{$\begin{array}{l}\text { Weight } \\
\text { (AVG } \pm \text { SD) }\end{array}$} & \multirow[t]{2}{*}{ Pde6b } & \multicolumn{4}{|c|}{ Experimental Use $(n)$} \\
\hline & & & & & & Behavioral Tests & WB & $\mathrm{IF}$ & $\overline{Q-P C R}$ \\
\hline \multirow[t]{2}{*}{ Vehicle } & $\mathrm{Eu}$ & 10 & $6 / 4$ & $31.5 \pm 7.2$ & 0 & 10 & 8 & 4 & 6 \\
\hline & Ts65Dn & 10 & $5 / 5$ & $25.7 \pm 3.2$ & 0 & 10 & 8 & 4 & 6 \\
\hline \multirow[t]{2}{*}{ InRapa } & $\mathrm{Eu}$ & 10 & $6 / 4$ & $31.8 \pm 6.8$ & 0 & 10 & 8 & 4 & 6 \\
\hline & Ts65Dn & 10 & $6 / 4$ & $28.9 \pm 5.6$ & 0 & 10 & 8 & 4 & 6 \\
\hline
\end{tabular}

\section{InRapa treatment}

6-month old Ts65Dn mice and euploid were administered intranasal rapamycin (InRapa; Rapamune, Pfizer, New York, NY, USA) and Vehicle (Veh; saline with 1\% DMSO) for 12 weeks. Mice were divided in 4 experimental groups euploid and Ts65Dn treated with vehicle or rapamycin ( $n=10$ per group). The treatment was conducted 3 times per week, with a dose of $0.1 \mu \mathrm{g} / \mu \mathrm{l}$ of rapamycin solution or vehicle (Fig. 1) in $10 \mu \mathrm{l}(1 \mu \mathrm{g} /$ mouse). The treatment was well tolerated and no change in body weight or in the consumption of drinking water was observed. The rapamycin dose was chosen from a dose-response pilot study performed before the treatment. In the dose-response treatment the animals were divided in three groups ( $n=6$ per group) and treated with $0.01,0.05,0.1$ and $0.2 \mu \mathrm{g} / \mu \mathrm{l}$ of rapamycin. Our data demonstrated that the dose of rapamycin administered during the treatment, $0.1 \mu \mathrm{g} / \mu \mathrm{l}$, was able to partially inhibit mTOR (Ser2448) phosphorylation in mice hippocampus and frontal cortex (see Additional file 1). Rapamycin distribution in brain and plasma was investigated before treatment by UPLC-MS analysis. Briefly 6 euploids mice were treated by single intranasal delivery of rapamycin, with the dose of $1 \mu \mathrm{g} /$ mouse $(0.05 \mathrm{mg} / \mathrm{Kg} /$ mouse), or by single intraperitoneal injection (i.p.) with the dose of $50 \mu \mathrm{g} /$ mouse $(2.5 \mathrm{mg} / \mathrm{kg} /$ mouse $) .4 \mathrm{~h}$ after the treatment brain and blood were collect for analysis. In particular, for plasma isolation blood was collected in presence of EDTA and then centrifuged at $3000 \times \mathrm{g}$ for $15 \mathrm{~min}$ at $4{ }^{\circ} \mathrm{C}$.
Ultra-performance/pressure liquid chromatography- mass spectrometry (UPLC-MS) analysis

For the quantification of rapamycin in brain and plasma, a UPLC-MS analysis method was utilized. Collected biological specimens were prepared as follows. Brain samples $(\approx 100 \mathrm{mg})$ were homogenized by 20 strokes of a Wheaton tissue homogenizer using $200 \mu \mathrm{l}$ of a lysis buffer (30 mM Tris-HCl, $0.1 \mathrm{M} \mathrm{NaCl}, \mathrm{pH}$ 7.4). Further homogenization was obtained through sonication of the samples for $10 \mathrm{~s}$ 3-times in ice. Homogenized brain and isolated plasma $(100 \mu \mathrm{l})$ samples were then purified using an Ostro ${ }^{\mathrm{Ts}}$ Pass-through Sample Preparation Plate (Waters) to remove proteins and phospholipids, by following the instructions provided by the manufacturer. The samples were finally dried under vacuum at low temperature. The residue was resuspended in $50 \mu \mathrm{l}$ of water/acetonitrile (20:80) and $40 \mu \mathrm{l}$ were injected onto the instrument. Chromatographic separation was performed on a Waters Acquity H-Class UPLC system (Waters, Milford, MA, USA), including a quaternary solvent manager (QSM), a sample manager with flow through needle system (FTN), a photodiode array detector and a single-quadruple mass detector with electrospray ionization source (ACQUITY QDa). The column was a Zorbax Eclipse-Plus C8 $(4.6 \times 50 \mathrm{~mm}$, $1.8 \mu \mathrm{m}$ particle size). The mobile phase was composed of a $5 \mathrm{mM}$ ammonium formate aqueous solution (Solvent A) and 0.1\% formic acid in methanol (Solvent B). A gradient elution program was performed starting with $30 \%$ solvent A and 70\% solvent B for 3 min, up to $100 \%$ B

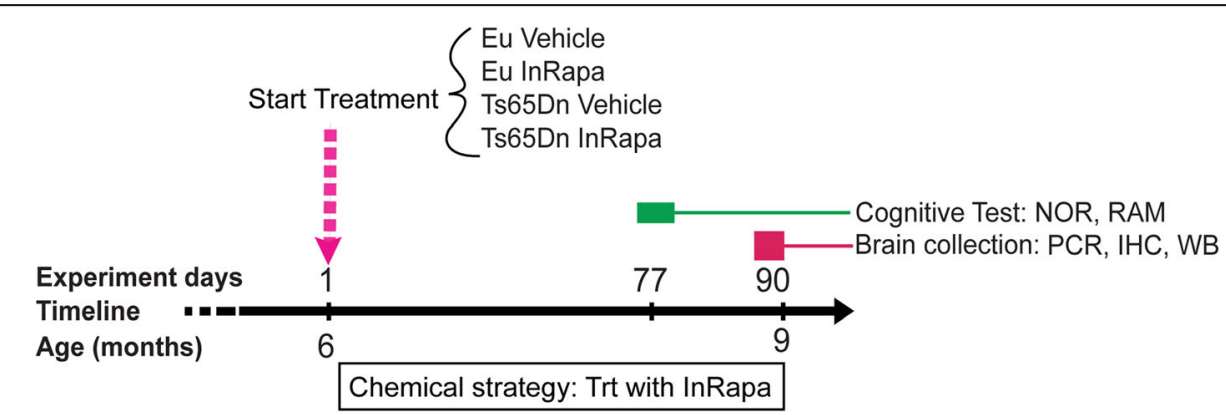

Fig. 1 Schematic of InRapa treatment. 6-month old Ts65Dn mice and euploid (Eu) were administered with intranasal rapamycin (InRapa; Rapamune, Pfizer) $1 \mu \mathrm{g} /$ mouse and Vehicle (Veh; saline with 1\% DMSO) for 90 days total. At day 77 cognitive tests (NOR and RAM) has been initiated while at day 90 mice has been sacrificed to perform PCR, IHC and WB on collected brain samples 
in $3 \mathrm{~min}$, followed by $2 \mathrm{~min}$ at $100 \% \mathrm{~B}$. The column was re-equilibrated to $30 \% \mathrm{~A} / 70 \% \mathrm{~B}$ for $4 \mathrm{~min}$. In these conditions rapamycin has a retention time of $5.4 \mathrm{~min}$. Mass spectrometric detection was set in the positive electrospray ionization mode using nitrogen as nebulizer gas. Analyzes were performed in Total Ion Current (TIC) mode in the mass range $400-1000 \mathrm{~m} / \mathrm{z}$. Capillary voltage was $0.8 \mathrm{kV}$, cone voltage $30 \mathrm{~V}$, ion source temperature $120{ }^{\circ} \mathrm{C}$ and probe temperature $600{ }^{\circ} \mathrm{C}$. QDa analysis detected the presence of rapamycin adducts with potassium, sodium and ammonium ions $\left([\mathrm{M}+\mathrm{K}]^{+} m / z=952.45\right.$, $[\mathrm{M}$ $\left.+\mathrm{Na}]^{+} m / z=936.45,\left[\mathrm{M}+\mathrm{NH}_{4}\right]^{+} m / z=931.45\right)$. The quantification of rapamycin adducts was performed by automatic peak area integration using a dedicated software (Empower3). A calibration curve was plotted using different amounts of rapamycin ( 0.5 pmoles to 200 pmoles), treated with the same procedure used for the samples. The curves (11 data points in duplicate) were linear with an $R^{2}$ value of $\approx 1.00$.

\section{Novel object recognition (NOR)}

The Novel Object Recognition (NOR) task is used to evaluate cognition, particularly recognition memory, in rodent models of CNS disorders. All experimental groups (Eu Veh, Ts65Dn Veh, Eu InRapa and Ts65Dn InRapa) were involved in the test procedures. This test is based on the spontaneous tendency of rodents to spend more time exploring a novel object than a familiar one. The task procedure consists of three phases: habituation, familiarization, and test phase. In the habituation phase at 1st day, each animal is allowed $10 \mathrm{~min}$ to freely exploring the open-field arena $(50 \mathrm{~cm}$ deep $\times 30 \mathrm{~cm}$ widths $\times 30 \mathrm{~cm}$ height) in the absence of objects. During the familiarization phase on the 2nd day, a single animal is placed in the open-field arena containing two identical objects (two balls), for $10 \mathrm{~min}$. To prevent coercion to explore the objects, rodents are released against the center of the opposite wall with its back to the objects. The experimental context is not drastically different during the familiarization and the test phase. In the test phase after $24 \mathrm{~h}$, the animal is returned to the open-field arena with two objects, one is the familiar object and the other is novel (ball + plastic brick) [34, 35]. The discrimination index and preference index percentage are recorded. Discrimination index (DI), allows discrimination between the novel (TN) and familiar (TF) objects [DI $=(\mathrm{TN}-\mathrm{TF}) /(\mathrm{TN}+\mathrm{TF})]$. The preference index $(\mathrm{PI})$ is a ratio of the amount of time spent exploring any one of the two objects in training phase $(\mathrm{A}, \mathrm{B})$ or the novel one in test phase $(C)$ over the total time spent exploring both objects, i.e., $\mathrm{A}, \mathrm{B}$ or $\mathrm{C} /(\mathrm{A}, \mathrm{B}+\mathrm{C}) \times 100(\%)$ in the test phase. Therefore, a preference index above $50 \%$ indicates novel object preference, below $50 \%$ familiar object preference, and $50 \%$ no preference [35].

\section{Radial arms maze (RAM)}

The Radial Arms Maze is composed of a central octagonal platform with eight arms extending from it like the spokes of a wheel [36]. All animals were familiarized with the maze for 3 days before training ( $\mathrm{Eu}$ Veh, Ts65Dn Veh, Eu InRapa and Ts65Dn InRapa; $n=10$ ). On these 3 days, they were placed in the maze for $10 \mathrm{~min}$ and could eat food rewards that were scattered throughout the maze. In our protocol, the version of the task was an alternated- baited maze procedure, where mice had to learn to visit only all the baited arms. Mice were given daily training sessions (one trial per session) over a 9-day period and day 10th was considered a Test Day. A daily training session started with the animal placed in the central area, once the mouse explored the baited arm and came back into the central area, the trial was ended. For all groups, a trial ended when one of the following conditions was reached: (i) the animal visited all baited arms, or (ii) the trial lasted for more than $10 \mathrm{~min}$. The maze was cleaned with absorbing paper between each animal to minimize the olfactory intra-maze cues. We evaluated the total number of working memory errors (WME), reference memory errors (RME) and latency to finish a trial made by the animals with respect to the training sessions. Distance travelled between groups have been recorded and analyzed showing no significant differences (Additional file 2).

\section{RNA extraction and quantitative real-time RT-PCR}

RNA was extracted from the frozen hippocampus in the all groups ( $n=6$ /group) using Tissue Total RNA Kit according to manufacturer's instructions (Fisher Molecular biology, Rome, Italy). RNA was quantified using the Biospec Nano spectrophotometer (Shimadzu, Columbia, MD, USA), and RNA was reverse transcribed using the cDNA High Capacity kit (Applied Biosystems, Foster City, CA, USA), including reverse transcriptase, random primers and buffer according to manufacturer's instructions. The cDNA was produced through a series of heating and annealing cycles in the MultiGene OPTIMAX 96-well Thermocycler (LabNet International, Edison, NJ, USA). Real time PCR (Q-PCR) using the following cycling conditions: 35 cycles of denaturation at $95{ }^{\circ} \mathrm{C}$ for $20 \mathrm{~s}$; annealing and extension at $60^{\circ} \mathrm{C}$ for $20 \mathrm{~s}$, using the SensiFAST ${ }^{\mathrm{Tm}} \mathrm{SYBR}^{\circ}$ No-ROX Kit (Bioline, London, UK). PCR reactions were carried out in a $20 \mu \mathrm{l}$ reaction volume in a CFX Connect Real Time PCR machine (Bio-Rad Laboratories, Hercules, CA, USA). Primers used for the evaluation of gene expression are reported in Table 2. Relative mRNA concentrations were calculated from the take-off point of reactions (threshold cycle, $\mathrm{Ct}$ ) using the comparative quantification method performed by Bio-Rad software and based upon the $\Delta \Delta \mathrm{Ct}$ method. Ct values for GAPDH expression served as a normalizing signal [37]. 
Sample preparation for Western blot and immunofluorescence Brain tissues of Ts65Dn and euploid mice $(n=8$ per group) after treatment were sagittally divided in right and left hemispheres. The right portion was used for Immunofluorescence studies and the left portion was used for molecular biology studies. For western blot and slot blot, the left-hippocampus were thawed in RIPA buffer (pH 7.4) containing $50 \mathrm{mM}$ Tris- $\mathrm{HCl}(\mathrm{pH} 7.4), 150 \mathrm{mM}$ $\mathrm{NaCl}, 1 \% \mathrm{NP}-40,0.25 \%$ sodium deoxycholate, $1 \mathrm{mM}$ EDTA, 0,1\% SDS, $1 \mathrm{mM}$ PMSF, $1 \mathrm{mM} \mathrm{NaF}$ and $1 \mathrm{mM}$ $\mathrm{Na}_{3} \mathrm{VO}_{4}$. Brains were homogenized by 20 strokes of a Wheaton tissue homogenizer. All the samples homogenate was centrifuged at $14,000 \times \mathrm{g}$ for $10 \mathrm{~min}$ to remove cellular debris. The supernatant was extracted to determine the total protein concentration by the $\mathrm{BCA}$ method (Pierce, Rockford, IL, USA).

\section{Western blot}

For Western blot, $30 \mu \mathrm{g}$ of proteins were prepared by adding in 2X Laemmli Buffer (Bio-Rad Laboratories, Hercules, CA, USA). The sample was heated at $100{ }^{\circ} \mathrm{C}$ for $10 \mathrm{~min}$. Electrophoresis was performed on the samples using a Criterion TGX Stain-Free 4-15\% 18-well gel in a Criterion large format electrophoresis cell (Bio-Rad Laboratories, Hercules, CA, USA) in TGS Running Buffer (Bio-Rad Laboratories, Hercules, CA, USA), for $60 \mathrm{~min}$ at $100 \mathrm{~V}$. Immediately after electrophoresis, the gel was placed on a Chemi/UV/Stain-Free tray and then placed into a ChemiDoc MP imaging System (Bio-Rad Laboratories, Hercules, CA, USA) and UV-activated based on the appropriate settings with Image Lab Software (Bio-Rad Laboratories, Hercules, CA, USA). For gels that would be later used in blotting, the software-selected activation time was $45 \mathrm{~s}$. Following electrophoresis and gel imaging, the proteins were transferred via the TransBlot Turbo semi-dry blotting apparatus (Bio-Rad Laboratories, Hercules, CA, USA) onto a nitrocellulose membrane. After transfer, the blot was imaged using the ChemiDoc MP imaging system using the Stain-Free Blot settings. This total protein signal was used as the basis for total protein normalization. Membranes were blocked with 3\% of bovine serum albumin (SERVA Electrophoresis $\mathrm{GmbH}$, Heidelberg, Germany) and incubated over night at $4{ }^{\circ} \mathrm{C}$ with primary antibody. An additional table shows the antibody details (see Additional file 3). All the membranes were incubated for $1 \mathrm{~h}$ at room temperature with secondary antibody horseradish peroxidase-conjugated anti-rabbit, anti-mouse or anti-goat IgG (1:5000, SigmaAldrich, St Louis, MO, USA). The blot was then imaged via the ChemiDoc MP imaging system using the Chemiluminescence settings. Subsequent determination of relative abundance via total protein normalization was calculated using Image Lab 6.0 software (Bio-Rad Laboratories, Hercules, CA, USA).

\section{Slot blot}

For the analysis of total 3-nitrotyrosine (3-NT) and 4-hydroxy-2-nonenal (HNE)-bound protein levels, $10 \mu \mathrm{l}$ of hippocampus homogenate were incubated with $10 \mu \mathrm{l}$ of Laemmli buffer containing 0.125 M Tris base $\mathrm{pH} 6.8,4 \%$ $(v / v)$ SDS, and $20 \%(\mathrm{v} / \mathrm{v})$ glycerol. The resulting samples (250 ng per well) were loaded onto a nitrocellulose membrane with a slot-blot apparatus under vacuum pressure. The membrane was blocked for $2 \mathrm{~h}$ with a solution of $3 \%$ $(w / v)$ bovine serum albumin in PBS containing $0.01 \%$ $(\mathrm{w} / \mathrm{v})$ sodium azide and $0.2 \%(\mathrm{v} / \mathrm{v})$ Tween 20 and incubated respectively with primary antibodies anti-HNE (Alpha diagnostic, San Antonio, TX, USA) and anti-3NT (Santa Cruz Biotechnology, Dallas, TX, USA) for $2 \mathrm{~h}$ at RT. Membranes were washed and incubated with anti-rabbit or mouse IgG alkaline phosphatase secondary antibodies (Sigma-Aldrich, St Louis, MO, USA) for $1 \mathrm{~h}$ at room temperature. The membrane was developed with Sigma fast tablets (5-bromo-4-chloro-3-indolyl phosphate/nitroblue tetrazolium substrate [BCIP/NBT substrate], Sigma-Aldrich, St Louis, MO, USA). Membranes were dried and the image was acquired using ChemiDoc XP image system and analyzed using Image Lab software (Bio-Rad Laboratories, Hercules, CA, USA).

\section{Immunofluorescence}

Brains were removed and immersed in $4 \%$ paraformaldehyde for $24 \mathrm{~h}$ at $4{ }^{\circ} \mathrm{C}$. Fixed brains were cryoprotected in successive $48 \mathrm{~h}$ with a solution of $20 \%$ sucrose and $0.02 \% \mathrm{NaN}_{3}$ at $4{ }^{\circ} \mathrm{C}$. Brains were frozen on a temperature-controlled freezing stage, coronal sectioned $(20 \mu \mathrm{m})$ on a sliding cryostat (Leica Biosystems, Wetzlar, Germany), and stored in a solution of PBS containing $0.02 \% \mathrm{NaN}_{3}$ at $4{ }^{\circ} \mathrm{C}$. Brain sections were mounted on glass slide. Once dried, sections were blocked with a solution containing $10 \%$ normal goat serum, $0.02 \% \mathrm{NaN}_{3}$, and $0.2 \%$ Triton X-100 in TBS. Slides were then incubated overnight at $4{ }^{\circ} \mathrm{C}$ with following antibodies: $\mathrm{p}$ (Ser 2448)-mTOR (mouse 1:500), p(Ser416)-tau (rabbit 1:500), amyloid- $\beta$ (B-4) (rabbit 1:500) (Bio-Rad Laboratories, Hercules, CA, USA; Santa Cruz Biotechnology, Dallas, TX, USA). Slides were then washed with TBS and then incubated with Alexa Fluor $-488 \mathrm{~nm}$ and $-594 \mathrm{~nm}$ secondary antibodies (Invitrogen Corporation, Carlsbad, CA, USA) at 1:1500 for $2 \mathrm{~h}$ at room temperature. Slides were then washed again and incubated with DAPI (1:10.000). One slide per group was stained omitting primary antibodies to establish nonspecific background signal. Cover slips were placed using a drop of Fluorimount (Sigma-Aldrich, St Louis, MO, USA).

All slides were imaged using Zeiss AXio (Carl Zeiss, Oberkochen, Germany). All immunolabeling acquisition intensities, field sizes, and microscopy settings were kept consistent across all images. Images were analyzed using 
ImageJ. Image montages for Figures were collated in Illustrator and Photoshop Cs6 (Adobe System, San Josè, CA, USA) software programs and were based upon cells that most closely approximated the group means.

\section{Experimental size and statistical analysis}

Behavioural tests (NOR and RAM) were performed using 10 mice per group (Ts65Dn Veh and Rapa; Eu Veh and Rapa). Q-PCR was achieved one time with cDNA from 6 mice per group (Ts65Dn Veh and Rapa; Eu Veh and Rapa). Each immunoblot experiment was performed at least three times using 8 samples per group. Immunohistochemistry analyzes were performed using at least $10 \mathrm{sec}-$ tions per brain of 4 mice per group. Details on sample size are summarized in Table 1). All statistical analyses were performed using a non-parametric one-way ANOVA with post hoc Bonferroni t-test. Further to determine how our data are affected by genotype (DS), treatment (InRapa) and their interaction we accomplished a two-way ANOVA analysis (data are reported in a table as Additional file 4). Data are expressed as mean \pm SD per group. All statistical analyzes were performed using Graph Pad Prism 7.0 software (GraphPad, La Jolla, CA, USA).

\section{Results}

\section{Intranasal delivery reduces peripheral rapamycin concentration}

To test the advantage of intranasal delivery in comparison to intraperitoneal (i.p.) injection, we treated mice once by the intranasal route, with the dose of $1 \mu \mathrm{g} / \mathrm{mouse}$ $(0.05 \mathrm{mg} / \mathrm{Kg} / \mathrm{mouse})$, and by i.p. $50 \mu \mathrm{g} / \mathrm{mouse}(2.5 \mathrm{mg} / \mathrm{kg} /$ mouse) as previously reported [20]. To note, InRapa dose is about 50-times lower than i.p injection dose. After $4 \mathrm{~h}$ of treatment we sacrificed mice and analyzed brain and plasma, from InRapa and i.p. treated animals, by UPLC-MS, to evaluate rapamycin distribution. Our analysis demonstrates that InRapa treated mice showed a brain concentration of rapamycin of $5.0 \pm 1.0 \mathrm{ng} / \mathrm{g}$ after $4 \mathrm{~h}$, while the plasma concentration was $6.7 \pm 1.3 \mathrm{ng} / \mathrm{ml}$ (see Additional file 5). In contrast, animals treated by i.p. injection showed a rapamycin brain concentration of 11.1 $\pm 1.7 \mathrm{ng} / \mathrm{g}$ and a plasma concentration of $890.5 \pm 98.1 \mathrm{ng} /$ $\mathrm{ml}$ (see Additional file 5). Collectively, our data demonstrate that rapamycin delivered by intranasal route reached a therapeutic brain concentration comparable to that obtained by i.p. injection but with an extremely lower distribution at plasma level. Therefore, these results, coupled with the analysis by WB of mTOR inhibition in liver and heart tissue, which showed no changes between Ts65Dn rapamycin and vehicle treated groups (see Additional file 6), suggest that InRapa delivery might not yield consistent side effects in peripheral organs.
InRapa improves cognitive performances in Ts65Dn mice To evaluate the effects of InRapa treatment on cognitive performances mice were subjected before the end of the treatment to hippocampal-based tasks, novel object recognition test (NOR) and eight-arms radial arms maze test (RAM), to test spatial learning and working memory, at first, to assess memory status differences between treated (InRapa) and untreated (Veh) animals, we performed the NOR tests. Our data show that Eu animals, both vehicle and rapamycin treated groups, demonstrate a PI above $50 \%$, while Ts65Dn mice treated with vehicle exhibit a PI slightly below $50 \%$ as result of hippocampal alterations. Interestingly, InRapa treatment is able to recover PI in Ts65Dn mice (increased about 70\%; $p=0.04$ ) and present a significant difference with Ts65Dn Veh mice, suggesting a recovery of hippocampal functions after InRapa administration (Fig. 2a). In addition, the impairment of cognition in Ts65Dn Veh is demonstrated by the significant reduction of DI $(20 \% ; p=0.08)$ (Fig. 2b) when compared to Eu Veh, while Ts65Dn InRapa group, demonstrate increased DI in comparison with Ts65Dn Veh group (about 20\%, $p=0.019$ ). The analysis of data by two-way ANOVA demonstrate that PI values are not affected by genotype or treatment variables, while their interaction account for the $17.90 \%(p<0.024)$ of the total variance. As far as DI results, genotype significantly account for the $25.92 \%$ (0.0016) of the total variance, while InRapa treatment do not affect data. The interaction between genotype and treatment significantly account for the $21.02 \%(0.0039)$ of the total variance.

The effects of InRapa on the working and reference memory was further evaluated by the radial arm maze (RAM) test. In 9 days of trial and in the test-day (day 10) we measured three different parameters (i) the time that all mice spend to reach all the 4 beads (Latency, min) (Fig. 2c, d); (ii) the reference memory errors, entry to an empty arm (Fig. 2e, f); (iii) the working memory errors, repeat entries to arms of the maze already visited (Fig. $2 \mathrm{~g}, \mathrm{~h}$ ). At day 1 all the mice spent an equal time to reach the beads and they showed no significant differences in latency and reference memory errors. At the day 10 Ts65Dn Veh showed poor acquisition ability, measured as increased in latency $(50 \%, p=0.0015)$ and as well as in working $(80 \%, p=0.042)$ and reference ( $40 \%, p=0.021)$ memory compared to Eu Veh group. On the other hand, the number of errors (working and reference memory) and the latency was lowest for $\mathrm{Eu}$ Veh, Eu InRapa and Ts65Dn InRapa groups and this effect was persistent during testing and was evident especially at day 10 . Indeed, if the attention is focused on day 10 (considered as Test Day), Ts65Dn treated with InRapa showed a decreased latency $(45 \% ; p=0.07)$ as show in Fig. $2 \mathrm{~d}$ and reference memory errors $(40 \%$, $p=0.013$ ) (Fig. 2h) compared to Ts65Dn Veh. A 

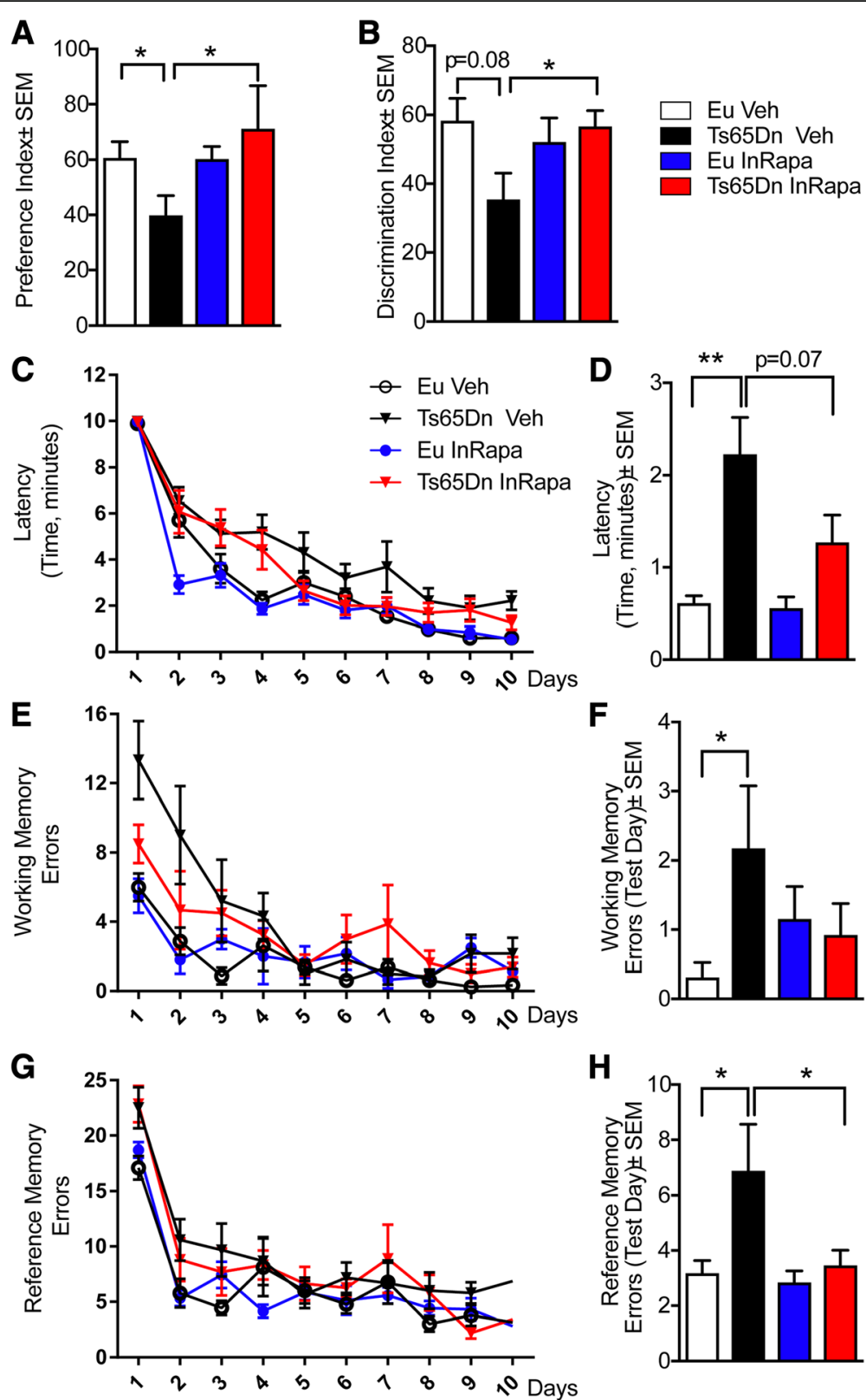

Fig. 2 InRapa improves cognitive performances in TS65Dn mice. Panel a and $\mathbf{b}$ represent data of the novel object recognition test. Values shown in the bar graph are in (a) Preference index and in (b) Discrimination index (data presented are mean \pm SEM $n=10 /$ group). Statistical significance was determined using one-way ANOVA and post hoc Bonferroni t-test $\left({ }^{*} p<0.05,{ }^{* *} p<0.01\right)$. Panels from $\mathbf{c}$ to $\mathbf{h}$ represent Radial Arm Maze (RAM) results for our treatment groups of treatment. The red and black triangles are data from Ts65Dn mice treated with InRapa and Veh solution. The blue filled circles are data from Eu mice treated with InRapa and the empty circle are data from Eu mice treated with Veh solution. Panel c represents the latency of the mice on each trial (one trial per day). Panel $\mathbf{d}$ represents bar diagram showing latency during the test day (day 10). Panel e represents the working memory errors committed by mice on each trial (one trial per day). Panel $\mathbf{f}$ represents bar diagram showing working memory error during the test day (day 10). Panel $\mathbf{g}$ represents the reference memory errors committed by mice on each trial (one trial per day). Panel $\mathbf{h}$ represents bar diagram showing reference memory error during the test day (day 10) values shown in the bar graph are the mean of 10 samples per each group

decreasing trend (not significant) for working memory errors $(50 \% ; p=0.12)$ was evident in Ts65Dn treated with InRapa (Fig. 2f) compared to Ts65Dn Veh. These results showed a partial recovery in cognition for Ts65Dn treated with InRapa. The analysis of RAM results by Two-way ANOVA show that genotype significantly account for the $35.71 \%(p=0.0004)$ and the $21.71 \%(0.0034)$ of the total variance of latency and reference memory results, respectively, while InRapa treatment significantly account for the $20.91 \%$ $(p=0.0039)$ of the total variance of reference memory results. The interaction between genotype and treatment 
significantly account for the $13.45 \%(0.0171)$ of the total variance of reference memory data only.

The results obtained by NOR and RAM tests demonstrate a significant effect of InRapa in Ts65Dn group compared to Veh group, supporting that a targeted rapamycin treatment is able to partially restore memory in Ts65Dn mice.

\section{InRapa decreases mTOR hyperactivation and induces autophagy}

We recently showed a pathological mTOR hyper-activation in Ts65Dn mice at 6 months of age compared with euploid controls [22]. Since long-term mTOR activation leads to neuronal dysfunction and cell death, we hypothesized that inhibition of p-mTOR in Ts65Dn mice would ameliorate the detrimental effects of chronic over-activation. Overall, our data show that intranasal delivery of the mTOR inhibitor rapamycin was able to target and modulate mTOR kinase activity in the hippocampus (Fig. 3 A-D) without affecting body weight as reported in Table 1. In particular, the biochemical analysis performed in the four groups of comparison demonstrate at first that Ts65Dn Veh mice compared with Eu Veh mice show an increase of mTOR phosphorylation at Ser2448 (69\%; $p=0.036$ ) (Fig. 3d). Similarly, p-mTOR (Ser2448) staining in the neuronal layer of CA3 in Ts65Dn mice Veh is significantly increased compared with $\mathrm{Eu}$ mice treated with Veh (101\%; $p=0.021)$ (Fig. 3a.1-5, B). The administration of InRapa in Ts65Dn mice is able to partially decrease mTOR phosphorylation at Ser2448 in comparison with Ts65Dn Veh mice $(82 \% ; p=0.014)$ rescuing the activity of mTORC1 to physiological levels as demonstrated by the comparison with Eu mice (Fig. 3d). Such results are confirmed by IF analysis that show a decrease of p-mTOR in Ts65Dn mice after InRapa of about 98\% $(p=0.002)$ (Fig. 3a.5-7, B). Accordingly, the analysis of dentate gyrus, by IF, demonstrate a trend of increase of mTOR phosphorylation in Ts65Dn mice Veh compared to euploids, which decrease after the treatment. The two-way ANOVA analysis of mTOR phosphorylation data show that genotype accounts for the $12.46 \%$ of the total variance $(p=$ 0.022 ), while InRapa treatment significantly accounts for the $20.38 \%$ of the total variance, no significant interaction between the two factor is present. Results on the reduced mTOR activation in Ts65Dn treated with rapamycin are confirmed also by real-time PCR. Indeed, Ts65Dn Veh mice compared with $\mathrm{Eu}$ Veh mice show a significant increase of mTOR gene expression (30\%; $p=0.024)$; in contrast, rapamycin administration is able to decrease the mTOR gene expression in Ts65Dn by 30\% $(p=0.019)$ and this reduction is comparable to Eu groups (Fig. $3 \mathrm{~h}$ ). However, alteration in mTOR gene expression do not yield changes in protein levels between groups. Rapamycin is considered a strong and specific inhibitor of mTORC1 activity, mTORC2 was originally considered insensitive to rapamycin administration. However, prolonged treatment with rapamycin also was shown to be able to inhibit mTORC2 [38]. Our analysis of mTORC2 activity, indexed by phosphorylation of mTOR at Ser2481, show no alteration between $\mathrm{Eu}$ and Ts65Dn mice either with or without InRapa administration $(10.3 \% p=0.8$ and $21.9 \% p=0.23$ respectively), supporting the low sensitivity of mTORC2 to rapamycin treatment (Fig. 3d).

mTORC1 is directly involved in regulating the activity of two components of the protein synthesis machinery, including the ribosomal S6 kinase 1 (S6 K1) and the eukaryotic translation initiation factor 4E-BP1. Active mTORC1 leads to the phosphorylation of p70S6K at Thr389, which in turn can exert its kinase activity on the $\mathrm{S} 6$ ribosomal protein, involved in protein translation [8]. Our data show, that hyperphosphorylated mTORC1 lead to the hyperphosphorylation of p70S6K in Ts65Dn mice compared to $\mathrm{Eu}$ animals (57\%; $p=0.0002$ ), while InRapa, despite an increase of protein levels, is able to reduce $\mathrm{p} 70 \mathrm{~S} 6 \mathrm{~K}$ activation to $\mathrm{Eu}$ values, suggesting the full restoration of the mTOR pathway $(90 \% ; p=0.0007)$ (Fig. 3e). The two-way ANOVA analysis shows that genotype do not significantly account for the total variance of p-P70S6K, while InRapa treatment significantly accounts for the $53.30 \%(p<0.0001)$. The interaction between genotype and treatment accounts for the $21.14 \%$ of the total variance $(p<0.001)$

In parallel, mTORC1 is a negative regulator of autophagy by directly phosphorylating and suppressing the kinase complex Ulk1/Atg13/FIP200 required to promote autophagosome formation [39]. Autophagy plays a crucial role in the removal of toxic/aggregated proteins, such as $\mathrm{A} \beta$ and $\mathrm{p}$-tau aggregates, and damaged organelles. The alteration of autophagy is reported in various neurodegenerative and lysosomal storage disorders and has been extensively demonstrated in DS [39-42]. A common molecular marker to evaluate the rate of autophagosome formation is represented by the ratio of the isoform II to isoform I of LC3, a microtubule associated protein, involved in phagophore elongation and closure [43]. Our results support the idea that, mTORC1 hyper-phosphorylation lead to decreased autophagosome formation as observed by reduced LC3 II (33\%; $p=0.04)$ and also, its gene expression (about 50\%; $p=0.07$ ) in Ts65Dn mice (Veh) compared with $\mathrm{Eu}$ animals. InRapa treatment in Ts65Dn was able to rescue the LC3 II protein levels, as demonstrated by its increase about $27 \%(p=0.012)$ when compared to Ts65Dn Veh mice, therefore retrieving autophagy function to physiological condition (Eu Veh) (Fig. 3F). The two-way ANOVA analysis shows that genotype significantly accounts for the $17.38 \%(p<0.034)$ of the total variance of $\mathrm{p}-\mathrm{P} 70 \mathrm{S6} \mathrm{K}$, while treatment has not significant effect $(p=0.067)$. The interaction between genotype and 


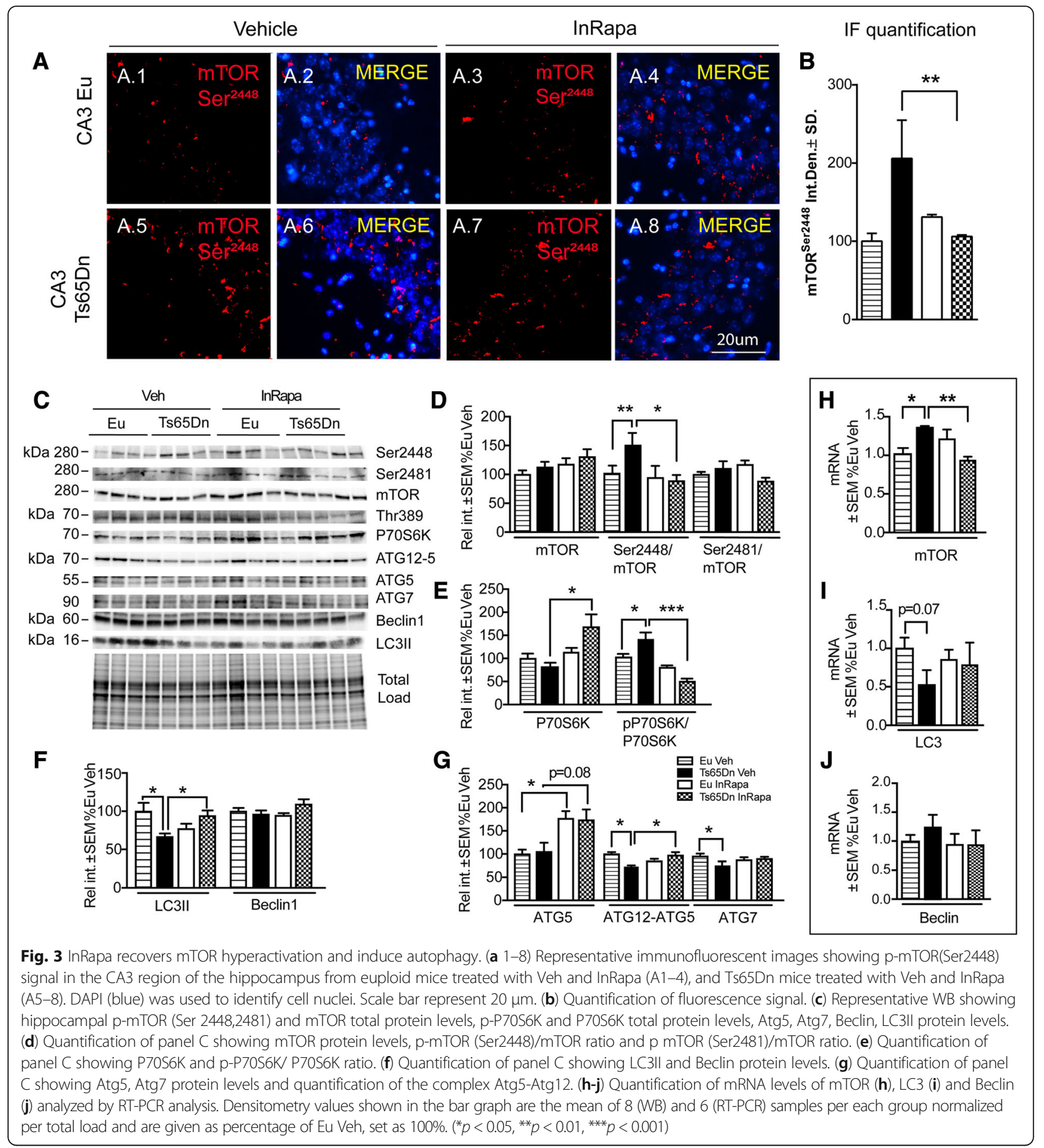

treatment accounts for the $35.12 \%(p<0.001)$ of the total variance.

In addition, this result is supported by an increasing trend (not significant, $p=0.09$ ) for LC3 gene expression in Ts65Dn treated with rapamycin (Fig. 3I). So far, the molecular levels of Beclin1, involved in autophagosome induction, and of Atg7, Atg5 and Atg12/Atg 5 complex, involved in autophagosome elongation, are currently employed as further indices of autophagy induction [43]. We show a significant reduction in Ts65Dn Veh mice compared to Eu Veh for both Atg7 levels (26\%; $p=0.043)$ and Atg5/Atg12 complex levels (25\%; $p=0.0038$ ) (Fig. 3G). InRapa treatment in Ts65Dn was able to recover the alteration of these autophagy-related markers to levels observed in euploid animals, despite Atg7 levels. Indeed, we found a $22 \%(p=0.0097)$ increase 
in Ts65Dn mice InRapa compared with Ts65Dn Veh for Atg12/Atg5 complex levels and a $68 \%(p=0.08)$ trend of increase in Ts65Dn mice InRapa compared with Ts65Dn Veh for Atg5 protein levels (Fig. 3g). The analysis of Atg12/Atg 5 complex data by two-way ANOVA show, as well as for LC3 II, that genotype significantly accounts for the $10.27 \%(p<0.0065)$ of the total variance, while treatment has not significant effects $(p=0.086)$. The interaction between genotype and treatment accounts for the $52.76 \%$ of the total variance $(p<0.001)$. No alterations of Beclin1 were observed both in gene expression and protein (Fig. 3J). Therefore, intranasal treatment by inhibiting mTOR phosphorylation allowed the recovery of autophagy-related markers alterations to the levels observed in Eu animals.

\section{InRapa reduces aberrant APP levels and APP processing}

The DS population demonstrate that the early accumulation of $A \beta$ peptide plays a key toxic role in the brain resulting in AD-like cognitive decline [1, 2, 5, 44, 45]. $\mathrm{A} \beta$ is the product of the proteolytic cleavage of APP, which, among the triplicated genes in DS, is considered the most toxic candidate that contributes to the pathogenesis of AD in DS individuals. The overexpression of APP in DS was shown by previous studies in both humans and mouse samples [4-6, 46]. We analyzed the hippocampus of Ts65Dn and Eu mice after InRapa treatment to investigate changes in APP gene expression, APP protein levels and its metabolites, and $A \beta$ peptide levels. At first, we employed the IF technique with the anti-A $\beta$ (B4) antibody, which recognize both $A \beta$ peptides and APP gene product. This analysis shows an increase of fluorescence in Ts65Dn mice compared to $\mathrm{Eu}$ mice (Veh groups) in the CA3 region $(90 \%, p=0.014$; Fig. $4 \mathrm{a} .1-5, \mathrm{~B})$ and in the dentate gyrus $(53 \%, p=0.08)$. While InRapa treatment decreases the levels of about $103 \%(p=0.0017$; Fig. 4a.5-8, B) in the CA3 region and of about $55 \%(p=0.027$, Additional file 7$)$ in the dentate gyrus. In order to evaluate the contribution of APP or $A \beta$ to IF signal changes, we performed a WB analysis using a different array of antibodies (Fig. $4 \mathrm{~b}$ ). The specific analysis of APP shows, as expected, an increase $(26 \% ; p=0.025)$ in Ts65Dn mice compared to euploids but a restoration of the signal (32\% reduction; $p=0.0065)$ in the same animals after InRapa treatment (Fig. 4d). The analysis of $\mathrm{A} \beta$ oligomers (at 25 and $50 \mathrm{kD}$ ) demonstrated an increase in Ts65Dn mice (about 50\% and $30 \%$ respectively; $p=0.06$ and $p=0.048$ ), which was significantly reduced by InRapa treatment $(70 \% p=0.035$ and $40 \% p=0.029$ ) (Fig. 4f). These data are particularly intriguing since previous studies showed conflicting results about increased $A \beta$ levels in Ts65dn mice at any age [47-49]. In order to investigate whether the decrease of APP protein levels after InRapa treatment were associated with reduced gene expression, we performed RT-PCR analysis demonstrating the same trend observed by IF and WB analysis: a $90 \%$ increase $(\mathrm{p}=0.08)$ in Ts65Dn mice Veh compared to $\mathrm{Eu}$ Veh, while a $102 \%$ reduction $(p=0.031)$ in Ts65Dn after InRapa administration (Fig. 4g). The two-way ANOVA analysis of $\mathrm{A} \beta$ data show that InRapa treatment account for the $14.67 \%$ $(p<0.0192)$ of the total variance of $\mathrm{A} \beta 25 \mathrm{kD}$ oligomers and for the $15.59 \%(0.0097)$ of the total variance of $A \beta 50$ $\mathrm{kD}$ oligomers.

Interactions account for the $15.50 \%(0.0164)$ and the 26.53\% (0.0011) of the total variance of $A \beta$ oligomers at 25 and $50 \mathrm{kD}$ respectively.

The APP processing can follow two different pathways that produce either non-amyloidogenic or amyloidogenic peptides. The non-amyloidogenic pathway is controlled by $\alpha$-secretases and lead to the formation of s-APP $\alpha$ and $\alpha$-CTF, while the amyloidogenic pathways lead to the formation of s-APP $\beta$ and $\beta-\mathrm{CTF}$, which can be furtherly cleaved by $\gamma$ secretase to form $A \beta$ [50]. The analysis of APP processing products demonstrates, in accordance with APP overexpression, the increased formation of $\alpha$-CTF $(29 \% ; p=0.030)$ and $\beta$-CTF peptides $(23 \%$; $\mathrm{p}=$ 0.048) in Ts65Dn compared to Eu mice treated both with Veh solution. The increased expression of $\alpha-C T F$ and $\beta-$ CTF, as observed for total APP levels, was recovered significantly by InRapa administration in Ts65Dn mice of about $31 \%(\mathrm{p}=0.029)$ and $29 \%(p=0.018)$, respectively, when compared to Ts65Dn Veh (Fig. 4D). The two-way ANOVA analysis demonstrate that genotype account significantly for the $17.20 \%(p<0.0064)$, the $13.74 \%(p=0.0103)$ and the $26.95 \%(p<0.0001)$ of the total variance of App, App $\alpha$-CTF and App $\beta$-CTF respectively, while InRapa treatment account for the $29.58 \%(p=0.0006)$, the $20.98 \%(p=0.0021)$ and the $40.05 \%(p<0.0001)$ of the total variance of App, App $\alpha$-CTF and App $\beta$-CTF. The interaction between genotype and treatment is significant only for App $\alpha$-CTF that account for the $14.42 \%$ ( $p=0.0088$ ) of the total variance.

In addition, the levels of $\beta$-secretase (BACE1), the rate-limiting enzyme in $\beta-C T F$ and $A \beta$ generation, were reduced after rapamycin treatment, in both Ts65Dn and $\mathrm{Eu}$ animals, suggesting that its expression is susceptible to rapamycin administration in a strain-independent manner (Fig. 4E). The two-way ANOVA analysis demonstrated indeed that InRapa treatment account for the $49.83 \%(p<0.0001)$ of the total variance.

\section{InRapa modulates tau hyper-phosphorylation and the expression of tau kinases}

To further investigate the efficacy of InRapa treatment to reduce AD-related pathological features in DS animals, we examined tau hyper-phosphorylation and the activation of the main kinases involved in its aberrant 


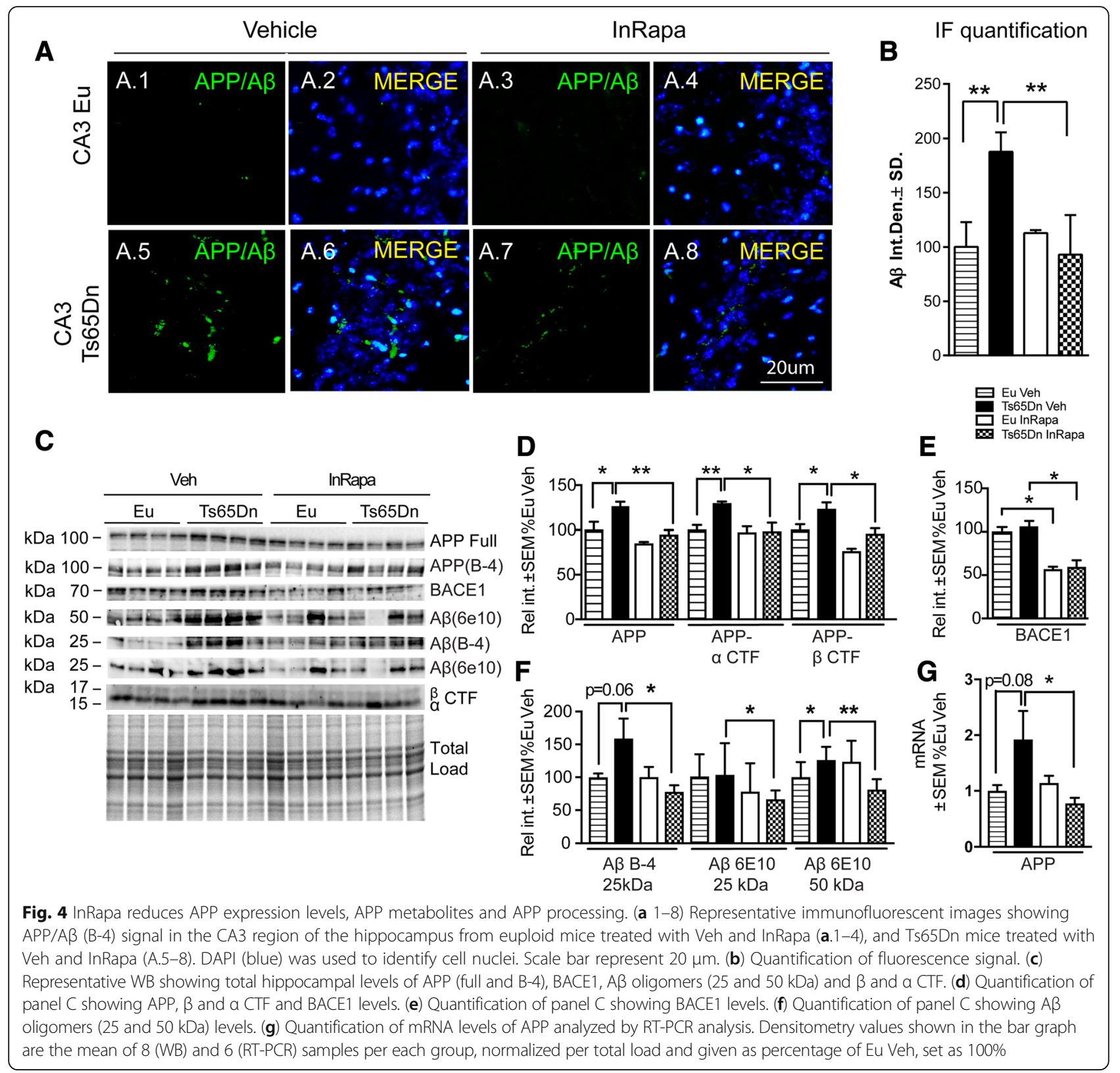

phosphorylation. The Ts65Dn mice show increased phosphorylation of tau on Ser416 (70\%; $p=0.027)$ compared with Eu (Fig. 5d). InRapa treatment on Ts65Dn mice, despite showing a slight increase of levels of tau proteins, demonstrate a robust decrease of tau phosphorylation, in Ser416, when compared to the same mouse strain treated with Veh $(80 \% ; p=0.011)$ (Fig. 5d). Similarly, p-tau (Ser416) staining in the neuronal layer of CA3 (Fig. 5a.1-5, B) and dentate gyrus (Additional file 7) are increased in Ts65Dn Veh mice compared with $\mathrm{Eu}$ Veh $(45 \%, p=0.033$ and $106 \%, \mathrm{p}=0.002)$. InRapa administration in Ts65Dn mice demonstrates the reduction of tau hyper-phosphorylation in Ts65Dn mice both CA3 $(90 \%, p=0.015$; Fig. 5a.5-8, B) and dentate gyrus (95\%, $p=0.004 ;$ Additional file 7) regions. The two-way ANOVA analysis of p-tau demonstrated that InRapa treatment, only account for the $16.64 \%(p=0.0184)$ of the total variance. Several proteins are involved in tau phosphorylation, such as GSK3 $\beta$ and DYRK1A, that function as direct kinases of tau, or RCAN1 that operate through the inhibition of calcineurin [51-55]. Akt is known to directly regulate GSK3 $\beta$ by phosphorylation of its inhibitory serine residue (Ser9). GSK3 $\beta$ kinase activity on tau phosphorylation, relies on protein levels and on the balance between the phosphorylation of its activatory (Tyr216) and inhibitory (Ser9) residues. GSK3 $\beta$ expression levels were higher in Ts65Dn cases compared to the appropriate $\mathrm{Eu}$ treated with Veh $(20 \% ; p=0.017)$. With 


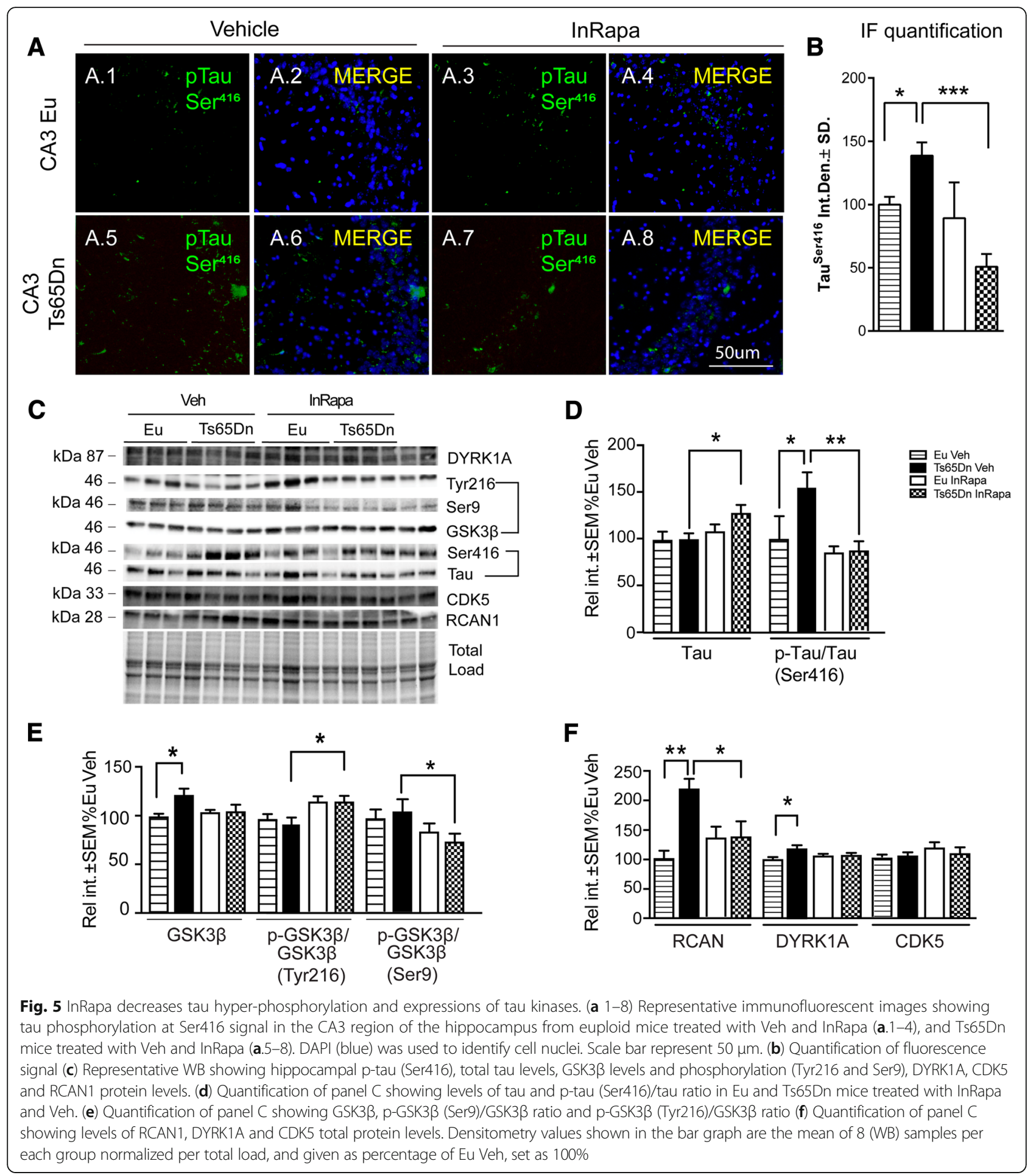

regard to GSK3 3 phosphorylation, we show slight but not significant increase of Ser9 and decrease of, while InRapa administration was able to improve GSK3 $\beta$ kinase activity by increasing Tyr216 and decreasing Ser9 phosphorylation (20\% $p=0.038$ and $25 \% p=0.031$ ) (Fig. 5e). The two-way ANOVA analysis of GSK3 $\beta$ phosphorylation levels show that InRapa treatment account for the $16.33 \%(\mathrm{p}=0.03)$ and the $27.60 \%(0.041)$ of the total variance of Ser9 and Tyr216 respectively.

As previously noted, tau phosphorylation could be induced directly or indirectly by DYRK1A and RCAN1, which are both encoded on chromosome 21. DYRK1A is expressed in fetal and adult brain and target tau at different serine residues, leading to its aberrant 
phosphorylation. Tau hyper-phosphorylation occurring in the brain from both Ts65Dn mice and DS subjects correlates with DYRK1A hyperactivation [56]. Our data confirm the over expression of DYRK1A in Ts65Dn mice (19\%; $p=0.035)$ due to Chr16 triplication, however this condition was not restored by InRapa administration, (Fig. 5f). DYRK1A data are affected by genotype, which account for the $13.62 \%$ of the total variance. Moreover, RCAN1 (regulator of calcineurin 1) is able to control tau dephosphorylation through the regulation of calcineurin. Increased RCAN1 levels result in decreased calcineurin activity and tau hyperphosphorylation. Our data report, as expected, the overexpression of RCAN1 in Ts65Dn Veh compared with Eu Veh $(118 \% ; \mathrm{p}=0.004)$, while InRapa treatment was able to reduce RCAN1 expression levels of Ts65Dn about 79\% (\% p = 0.03) when compared to Ts65Dn Veh (Fig. 5F). The two-way ANOVA analysis of RCAN1 levels show that genotype treatment account for the $21.52 \%(p=0.0033)$ of the total variance. In addition, CDK5 promotes p-tau accumulation in DS [57]. Increased levels of CDK5 was previously reported in the brains of young Ts65Dn [58], however our data show no significant alterations of CDK5 in Ts65Dn mice compared with $\mathrm{Eu}$ in both InRapa and Veh groups (Fig. 5f).

\section{InRapa leads to the recovery of mTOR upstream signalling}

mTORC1 is regulated upstream by positive inputs such as growth factors, hormones, chemokines, nutrients (e.g., glucose or amino acids), and cell energy status (ATP/AMP ratio). The regulation of mTORC1 by growth factors mainly involves insulin, which binds to insulin receptor (IR) and triggers the activation of the insulin receptor substrate 1 (IRS1). The phosphorylation of IRS1 on its activatory (Tyr632) or inhibitory (Ser307) residue modulates PI3K activation, which is negatively regulated by PTEN, a phosphatase protein and tensin homolog [8]. PI3K activation lead to increased PIP $_{3}$ levels that recruit Akt, to the membrane, where the latter is activated by phosphorylation of Thr308 and Ser473 residues. In turn, Akt positively regulates mTORC1 activity. Moreover, through a negative-feedback mechanism, mTORC1/ p70S6K mediates the inhibitory phosphorylation of IRS1 on a serine residue uncoupling the PI3K/Akt axis from insulin receptor signals [8].

The analysis of mTOR upstream signalling regulation shows no differences in levels and phosphorylation of PI3K (subunit p85; Tyr508) and increased levels of Akt in Ts65Dn Veh compared to Eu Veh $(40 \% ; p=0.022)$, but no differences in phosphorylation (Ser473) between all groups (Fig. 6b, c). Intriguingly, increased p-PTEN (Ser380/Thr382/383)/PTEN was found to be statistically significant in Ts65Dn InRapa compared with Ts65Dn Veh $(37 \% ; p=0.049)$ suggesting that despite decreased expression, PTEN activation is induced by InRapa, perhaps to better promote a correct regulation of the signal (Fig. 6d). The two-way ANOVA analysis show that genotype and interaction account for the 42.93\% $(p<0.0001)$ and for the $14.22 \%(p=0.005)$ of the total variance of Akt.

The analysis of the foregoing member of IRS1 pathway demonstrates that, despite increased protein levels of IRS1 in Ts65Dn mice compared to Eu (45\%; p = 0.049), a trend of inactivation in Ts65Dn mice, as indexed by decreased phosphorylation of its activation residue (Tyr632) and increased phosphorylation of its inhibitory residue (Ser307), is shown. Rapamycin delivered intranasally is able to reduce the inhibition (exerted by mTORC1 and p70S6K) on IRS1 by increasing its activation residue of phosphorylation $(80 \% ; p=0.03)$ and decreasing its inhibitory phosphorylation $(52 \% ; p=0.012)$ in Ts65Dn InRapa compared to Ts65Dn Veh animals (Fig. 6e). The two-way ANOVA analysis of IRS1 phosphorylation levels show that InRapa treatment account for the $62.94 \%(p<0.001)$ and the $13.89 \%(0.0476)$ of the total variance of Ser307and Tyr632, respectively.

The AMP-activated protein kinase (AMPK) is a key energy sensor and regulates cellular metabolism to maintain energy homeostasis. AMPK is an upstream signal of mTOR and its activation results in the inhibition of mTOR signalling, thereby suppressing protein synthesis, which is an important pathway by which AMPK conserves cellular energy during low energy states. In turn, prolonged mTOR hyper-phosphorylation on Ser2448 reduces AMPK activation [59]. Ts65Dn mice, in the presence of mTOR hyperphosphorylation, do not show increased pAMPK/AMPK signal, while InRapa treatment was able to reactivate AMPK as indexed by increased activatory phosphorylation on Thr172, of about 30\% ( $\mathrm{p}=0.02)$ (Fig. 6f).

\section{InRapa increases the expression levels of STX 1A and PSD95 synaptic proteins}

Prenatal and early post-natal synaptic defects have been largely documented several brain regions including the neocortex, hippocampus and cerebellum of fetuses with Down's syndrome and of mouse models of the disease [60-64]. Decreased numbers of presynaptic and postsynaptic terminals were previously observed during development in Ts65Dn hippocampus and Ts65Dn dentate gyrus has been shown to have a reduced number of neurons and deficient LTP $[60,65,66]$. To determine whether InRapa treatment result in the rescue of synapse failure, we examined the expression levels of syntaxin1A (STX1A) and PSD 95 in euploid and Ts65Dn mice. STX1A is neuronal plasma membrane protein that belongs to the soluble $\mathrm{N}$-ethylmaleimide-sensitive factor attachment protein receptor (SNARE) family and is 

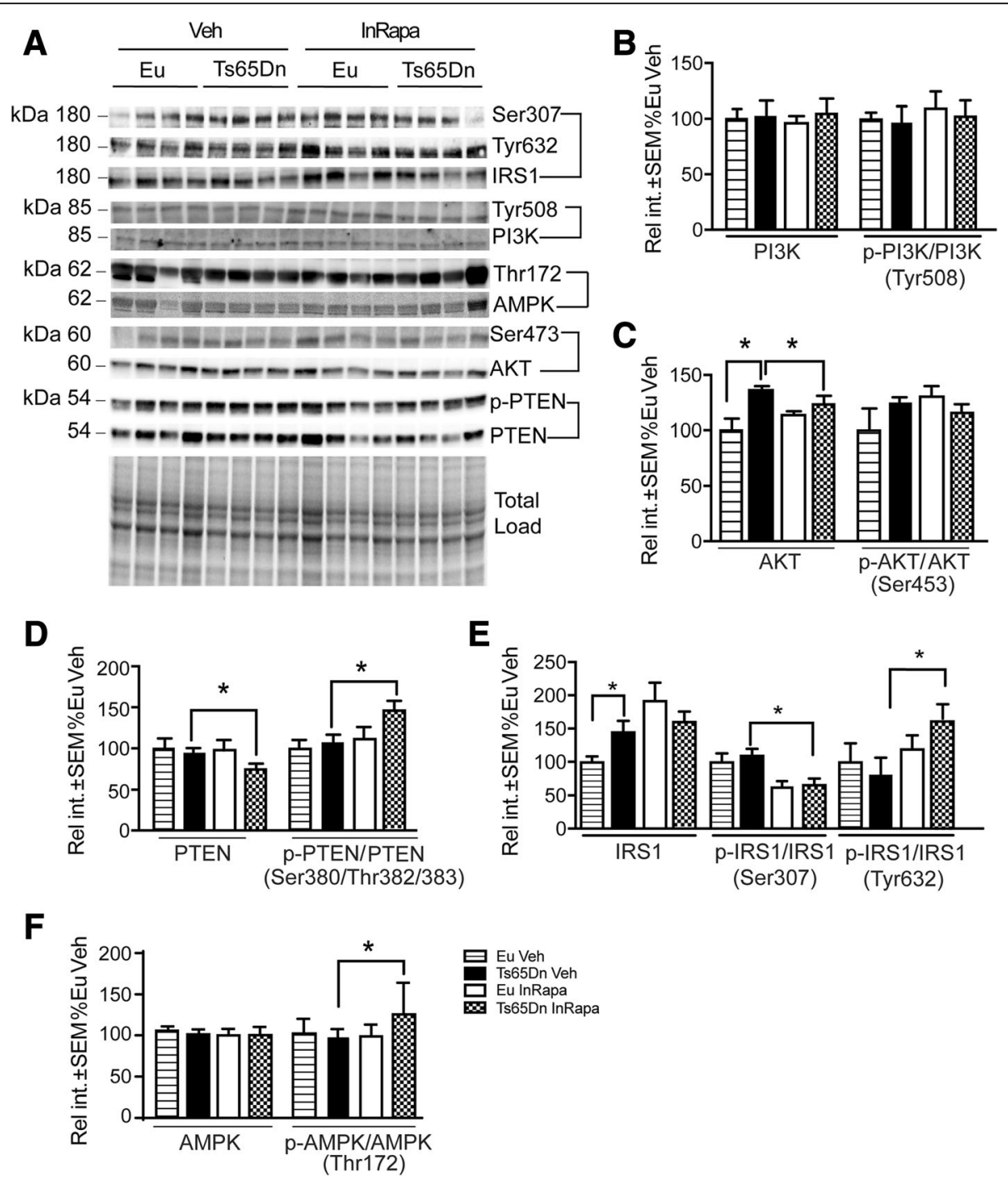

Fig. 6 InRapa recovers mTOR upstream signalling. a Representative WB showing hippocampal p-IRS (Ser307), p-IRS1 (Tyr632) and total IRS1 levels, p-PI3K(Tyr508) and total PI3K levels, p-AKT (Ser473) and total AKT levels, and p-PTEN (Ser380/Thr382/383) and total PTEN, p-AMPK (Ser172) and total AMPK. $\mathbf{b}$ Quantification of panel $\mathbf{a}$ showing hippocampal levels of PI3K and p-PI3K(Tyr508)/PI3K ratio. c Quantification of panel a showing AKT and p-AKT(Ser473)/AKT ratio. d Quantification of panel a showing levels of PTEN and p-PTEN (Ser380/Thr382/383)/PTEN ratio. e Quantification of panel a showing p-IRS1 (Ser307), p-IRS1 (Tyr632) and total IRS1 levels in Eu and Ts65Dn mice treated with InRapa and Veh. f Quantification of panel a showing AMPK and p-AMPK(Thr172)/AMPK ratio. Densitometry values shown in the bar graph are the mean of 8 samples per each group, normalized per total load and given as percentage of Eu Veh, set as 100\%

involved in vesicle trafficking, docking and/or fusion, playing a key role in neurotransmitter release. PSD 95, a membrane-associated guanylate kinase, is the major scaffolding protein in the excitatory postsynaptic density (PSD) and a potent regulator of synaptic strength. Thought the phosphorylation of 4EBP1 and p70S6K mTOR is able to regulates protein synthesis, influencing the expression of synaptic proteins. Our results show for STX1A expression a significant decrease in Ts65Dn Veh compared to euploid animals $(35 \%, p=0.0137)$, which is partially rescued $(20 \%$, ns) after rapamycin administration (Fig 7a-b). As far as PSD 95 we demonstrate a trend of decrease for its expression levels in Ts65Dn Veh mice compared to euploid Veh $(18 \%$, ns), while rapamycin treatment induces the overexpression of PSD 95 in both Ts65Dn $(50 \%, p=0.045)$ and Euploids (22\%, ns) (Fig. 7c-d). Our results are in line with previous studies showing reduced levels of synaptic protein in Ts65Dn mice and their induction after disease-modifying treatment leading to improved cognition [67-69]. Intriguingly, the two-way anova analyses of PSD95 show indeed that the treatment account for the $37.7 \%(p=0.0077)$ of the total variance. 

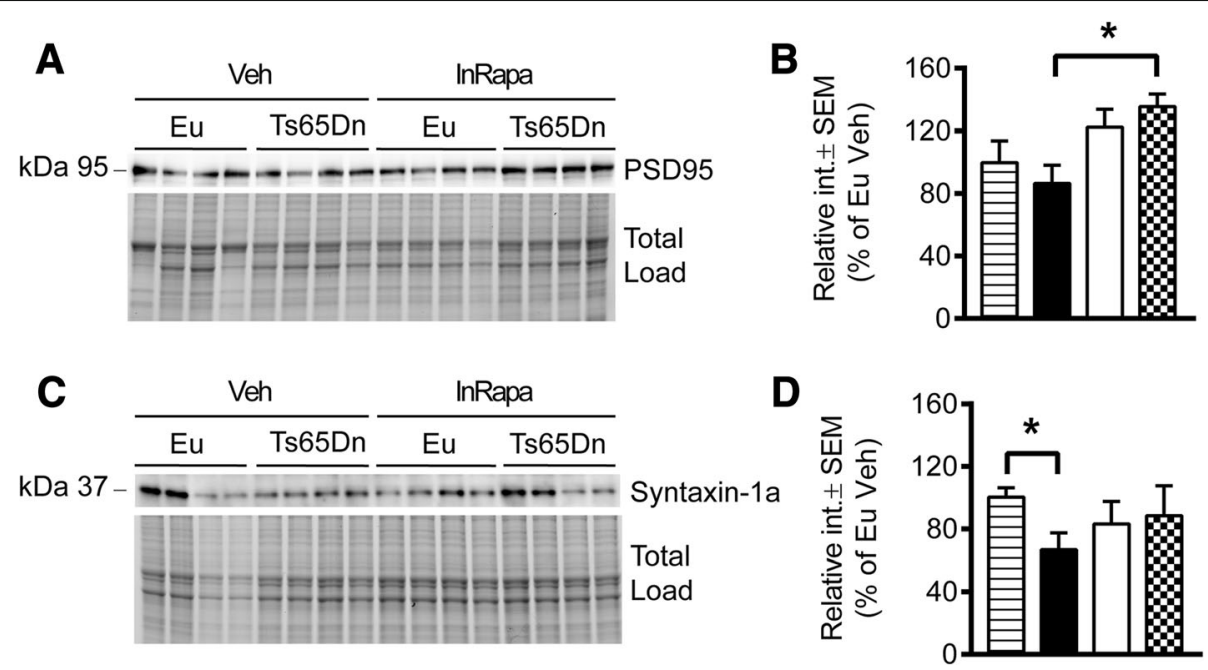

Fig. 7 InRapa increases the levels of PSD95 and STX1A synaptic proteins. a Representative WB showing hippocampal PSD95 levels. b Quantification of panel a showing hippocampal the expression levels of PSD95. c Representative WB showing hippocampal STX1A levels. d Quantification of panel c showing levels of STX1A. Densitometry values shown in the bar graph are the mean of 8 samples per each group, normalized per total load and given as percentage of Eu Veh, set as 100\%

\section{InRapa modulates protein oxidative damage and Lys63 poly-ubiquitinylation}

Previous studies by our group and others demonstrated that in DS brain alteration of autophagy is associated with increased oxidative stress (OS), which plays an important role in DS neuropathology [7, 9, 13, 22, 70]. However, the link between OS and autophagy is intricate, and increasing evidence suggests that the mTOR/ autophagy axis plays a dual role in the cellular response to OS $[71,72]$. We evaluated the levels of two protein oxidation markers, 4-hydroxy-2-nonenal protein adducts (HNE) and protein-bound 3-nitrotyrosine (3-NT) in the hippocampus of Ts65Dn and $\mathrm{Eu}$. We found a significant elevation of total 3-NT levels in Ts65Dn mice compared with Eu treated with Veh $(28 \% ; p=0.021)$, and such increase was reduced with InRapa treatment (23\%; $p=0.06$ ) (Fig. 8a). Further, a trend of increased HNE adducts to proteins was observe between $\mathrm{Eu}$ Veh and Ts65Dn Veh, and treatment with InRapa was able to significantly reduce such increase $(43 \% ; p=0.015)$ (Fig. $8 \mathrm{a})$. The two-way ANOVA analysis of 3NT levels show that genotype significantly account for the $31.05 \%(p=0.0007)$ of the total variance, while if we consider protein-bound HNE levels InRapa treatment and interaction account for the $47.01(p<0.0001)$ and for the $7.19 \%(p=0.043)$ of the total variance, respectively.

We also investigated the status of the ubiquitindependent proteolysis pathway through analysis of total protein poly-ubiquitinylation and the levels of chain linkage Lys48, considered to be a key signal for proteasome degradation, and chain linkage Lys63, known to have a role in protein degradation through the autophagy-lysosomal system [73]. However, we showed that Lys63 protein poly-ubiquitinylation might have a primary role in protein signalling in addition to protein degradation [10]. With regards to total protein poly-ubiquitinylation, no significant alteration was observed between DS and Eu animals with and without rapamycin treatment (Fig. 8c). However, if we discriminate the lysine residue of poly-ubiquitinylation we observed increased levels of Lys63 poly-ubiquitinylated proteins in Ts65Dn Veh mice compared to Eu Veh (13\%; $p=0.024)$, which are reduced in Ts65Dn InRapa compared to Veh (24\%; $p=0.0012$ ) (Fig. 8c). No significant changes were detected, among groups, for Lys48 poly-ubiquitinylated proteins. The two-way ANOVA analysis of Lys63 poly-Ub levels demonstrate that InRapa treatment and interaction account for the 32.71 $(p=0.0001)$ and for the $20.84 \%(p=0.0013)$ of the total variance, respectively.

\section{Discussion}

In the last decades, a significant increase of life expectancy has been observed in DS individuals due to improvement in health care. However, improved lifespan in DS is associated with an increased incidence of developing AD-like dementia [2, 74]. The triplication of APP represents a strong evidence on the influence of HSA21 trisomy in the progression to $\mathrm{AD}$-like cognitive decline in DS population. In addition, the triplication of tau kinases, such as DYRK1A and RCAN1, which act in parallel with aberrant mTOR pathway activation, contributes to increased tau phosphorylation and NFT formation $[72,75,76]$. The exact mechanisms by which triplication of genes on HSA21 lead to the early onset of AD in DS population remain still to be fully elucidated. 


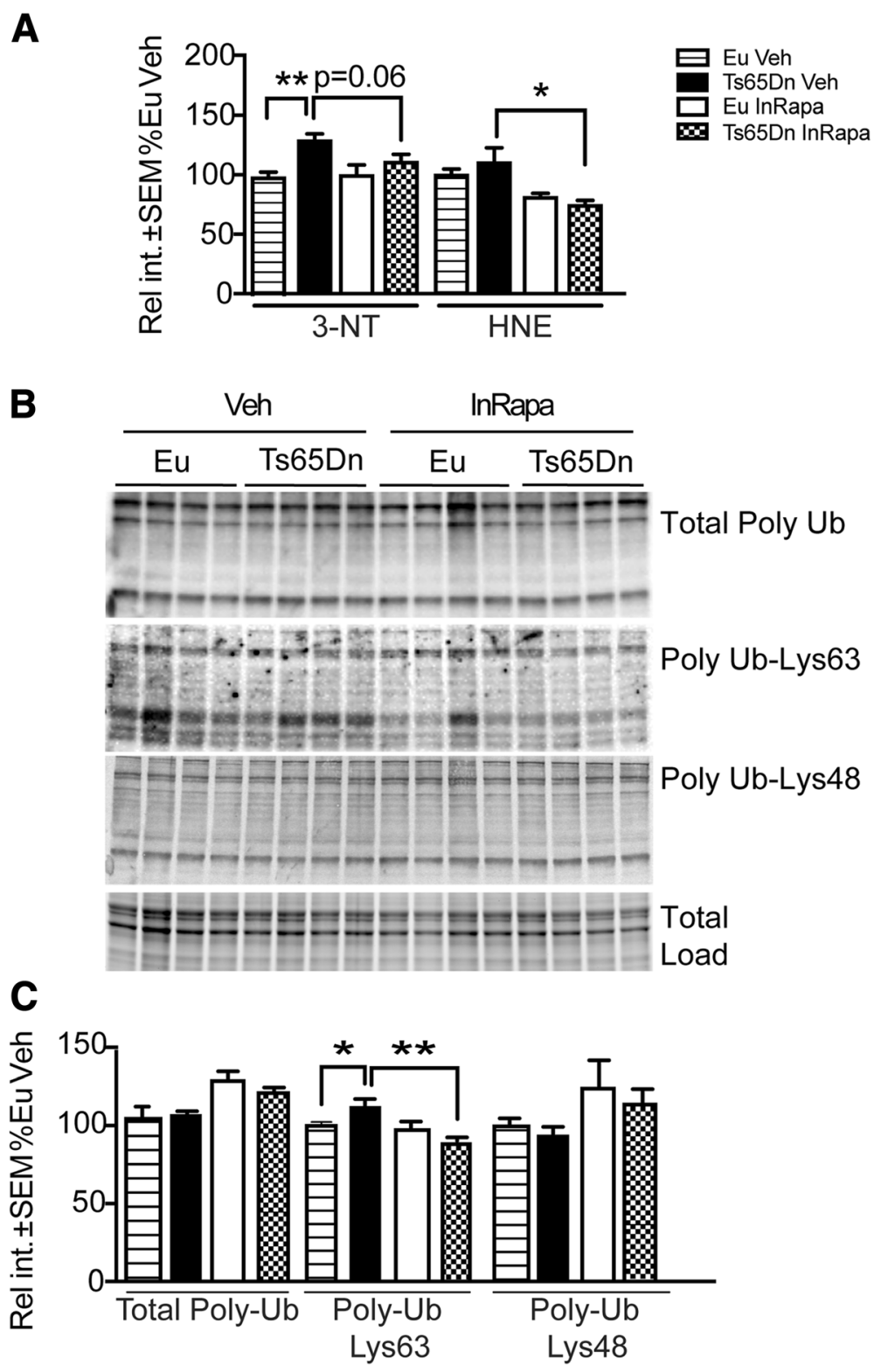

Fig. 8 InRapa reduces protein oxidative damage and K63 poly-ubiquitinylation. In panel a are shown the total hippocampal protein-bound 3-NT and HNE of Ts65Dn mice and Eu treated with Veh and InRapa analyzed by slot blot assay. In panel $\mathbf{b}$ are shown the hippocampal total poly-ubiquitin, poly-ubiquitin Lys63 and poly-ubiquitin Lys48 levels analyzed by Western blot. In panel $\mathbf{c}$ the quantification of panel $\mathbf{b}$ is reported. Densitometry values of each lane is the result of the sum of all the bands, analyzed by Image lab software as previously reported [10]. Graph values are the mean of 8 samples per each group, normalized per total load and given as percentage of Eu Veh, set as 100\%

Previous studies by our group and others demonstrated the hyper-activation of mTOR pathway in human brain from DS population and in Ts65Dn mouse model of the disease [13, 21, 22, 56, 77]. mTOR hyper-activation was found to be strongly associated with reduced autophagosome formation (most likely leading to impaired autophagy induction), increased $A \beta$ deposition and increased tau hyper-phosphorylation. Data collected by our studies support the key role of aberrant mTOR signalling in mediating the early progression of $\mathrm{AD}$ in $\mathrm{DS}$ population. Within this frame, the rescue of mTOR signalling by the administration of rapamycin, which has been previously tested in AD mouse models demonstrating favorable outcomes [19, $27,29-31,78-81$ ], represents a potentially valuable therapeutic strategy. Indeed, evidence obtained by the Oddo and Galvan laboratories [19,31] corroborated the positive effects of mTOR inhibition on hippocampal memory rescue in AD mice. In particular, the authors reported that chronic oral rapamycin treatment was able to prevent cognitive loss in two different transgenic mouse models of 
$\mathrm{AD}, 3 \times \mathrm{Tg}-\mathrm{AD}$ and $\mathrm{J} 20$, if given before robust plaque and tangle deposition. Memory improvement was associated with reduced $A \beta$ levels and tau-aggregation, as well as microglial activation [19, 31]. Based on these evidences, the initiation of an early treatment schedule is necessary to achieve brain protection in DS individuals, known to be at high risk of developing AD-like dementia. Moreover, the use of the intranasal route for the delivery of rapamycin to the brain holds a great potential as a non-invasive practical approach that circumvents systemic alterations and permits to maximal drug concentrations in the CNS, thereby avoiding the rapamycin-related immunosuppressant effects in the periphery [82-85]. This issue is particularly critical in DS pathological phenotypes, since trisomic individuals show depletion of immune system and lymphopenia [86-89]. In this scenario, by UPLC-MS analysis we were able to demonstrate that intranasal administration of rapamycin concentrated the drug in the CNS, where it exerted its inhibitory effects by reducing hippocampal mTORC1 hyper-phosphorylation of about 50\%, while, as expected, no effects were observed in peripheral organs analyzed. Of note, the rapamycin dosage delivered to the hippocampus of Ts65Dn was selected to not abolish mTOR activation but to rescue the signal at physiological levels, thus abrogating the pathological increase of mTOR and $\mathrm{p} 70 \mathrm{~S} 6 \mathrm{~K}$ phosphorylation along with the reduction of autophagy.

The restoration of mTORC1 activity after treatment demonstrated a significant effect on cognitive performance in Ts65Dn mice as indexed by RAM and NOR tests. Indeed, the RAM test revealed that mice were able to improve reference and working memory after rapamycin treatment. As well, the NOR test showed the improvement of mice preference index supporting the recovery of novelty-discriminating ability after rapamycin administration. Further, we suggest that the improved cognition, exerted by InRapa, is associated with the rescue of synaptic abnormalities previously observed in DS [60, 69]. Therefore, as previously proven in $\mathrm{AD}$, our data support the capability of rapamycin, if delivered chronically and intranasally before consistent brain damage, to improve memory and reduce cognitive decline in DS mice [31]. In order to understand the mechanisms leading to improved cognition after InRapa treatment we investigated the status of downstream targets of mTOR and the pathological features of AD-like neurodegenerative process.

Human and mouse studies suggest that APP is dosage sensitive as a function of aging and of brain regionalism $[4,6,46,50]$. In contrast, $A \beta$ accumulation becomes significant in humans only in the second/third decade of life, with some exceptions in a few childhood post- mortem observations $[2,75,76]$. Moreover, published data on $A \beta$ peptides levels in the brain of Ts65Dn mice are conflicting. This discrepancy might depend on the diversity of techniques, brain area analyzed and age of the samples. We observed an increase of $\mathrm{A} \beta$ oligomers at 25 and $50 \mathrm{kD}$ only, while previous studies focused on the identification of plaques, which are formed only at a very late stage of the disease. Within this scenario, our data suggest a primary role for APP and its processing in the neurodegenerative process occurring in DS [33, 47, 49, 50, 90]. Indeed, in Ts65Dn mouse, which develops AD-like neuronal endosomal pathology, the increase of APP- $\alpha C T F$ and APP- $\beta C T F$ between 6 and 12 months of age is likely to underlie the failure of NGF-mediated trophic support [6], and contribute to cognitive failure. Our analysis shows increased levels of APP in Ts65Dn mice at 9 months of age both in total hippocampus as well as in the CA3 region, together with the increased APP metabolites APP- $\alpha \mathrm{CTF}$ and APP- $\beta C T F$. InRapa administration is able to significantly reduce APP levels in the hippocampus of Ts65Dn mice and to decrease APP metabolites, suggesting the re-establishment of proper APP processing. Surprisingly, we also observed increased $A \beta$ oligomers in Ts65Dn mice and the reduction of such increase due to InRapa treatment. Two main mechanisms can be directly involved in the reduction of APP, APP metabolites and A $\beta$ in Ts65Dn mice after rapamycin treatment: i) the reduction of APP gene expression; ii) the rescue of protein synthesis/degradation pathways; ii) the restoration of key signalling pathways, including BACE1, PI3K/Akt, GSK-3 $\beta$, AMPK and IRS1, that regulate APP processing products formation/clearance $[8,12,14,39,72,91]$. Our data show, as expected, the increase of APP mRNA in Ts65Dn mice as a result of trisomy that demonstrate a significant decrease after InRapa treatment. In general, mTORC1 inhibition by rapamycin results in a reduction in global mRNA, indeed mTOR is able to bind a number of transcription factors (e.g. STAT3; PGC1 $\alpha$ ) that can regulate the expression of a broad range of target genes, comprising mTOR itself, whose aberrant modulation is known to be involved in neurodegeneration [92]. In agreement, our data supports a role for rapamycin in the down-regulation of APP transcription process. The transcription factor ETS2, encoded on Chr21, was demonstrated to transactivate the APP promoter, leading to its overexpression [93]. Previous studies revealed that the expression levels of ETS2 can be modulated by the mTOR pathway; therefore, rapamycin-induced mTOR inhibition, through the reduction of ETS2 levels, might reduce APP overexpression levels [94]. Besides, it is indeed equally important to highlight the significant increase of autophagosome formation observed in Ts65Dn mice after InRapa treatment. Our data demonstrate that mTOR inhibition lead to increased LC3II and Atg 12/5 levels supporting a crucial role for rapamycin in restoring the aberrant control of mTOR on autophagy. The observed induction of autophagosome formation in rapamycin treated DS mice is associated with the 
reduction of toxic aggregates burden and misfolded/oxidized proteins accumulation. Therefore, our results are in agreement with previous studies demonstrating that rapamycin-dependent stimulation of autophagy is likely one of the principal mechanisms by which the reduction of toxic protein aggregates, comprised of $A \beta$, aberrantly expressed APP and APP metabolites, is achieved in the brains of Tg-AD mice [18, 19, 23, 26, 31, 40, 79, 95]. Furthermore, the analysis of molecular pathways involved in APP processing demonstrated that rapamycin lead to the reduction of BACE1 levels and to the recovery of IRS1 signaling. Conversely, we obtained conflicting results concerning PI3K/Akt and GSK3 $\beta$ that suggest their modest involvement in APP metabolite reduction. The increased BACE1 activation is required for the cleavage of APP and the production of the neurotoxic $A \beta$ peptide during neurodegeneration, as demonstrated in $\mathrm{AD}$ mice and in our DS model $[4,5]$. On one side we could suppose that the reduction of BACE1 levels, observed after InRapa treatment, could be most likely related with the reduction of the APP substrate, accomplished by re-balanced synthesis/degradation. However, because such reduction is observed in both Ts65Dn and Eu mice, it is tempting to presume a close interaction between rapamycin/ mTOR and BACE1. The direct interaction of mTOR with IRS1 have been previously demonstrated and was shown to be deeply involved in the development of $\operatorname{AD}[13,20,21,96-$ 98]. Indeed, the failure of energy metabolism associated with the increase of brain insulin resistance are well-recognized contributors to $\mathrm{AD}$ neurodegeneration [96, 97, 99]. Our previous studies demonstrated that mTOR hyperphosphorylation and the subsequent overactivation of p70S6K kinase activity target IRS1 by increasing the phosphorylation on its inhibitory serine residues, which lead to the inactivation of the protein. Such effects contribute to the uncoupling of IRS1 from PI3K/Akt signalling and to the development of brain insulin resistance [13]. The rescue of mTOR signalling in Ts65Dn mice after InRapa leads to reduced IRS1 inhibitory phosphorylation sites; therefore, a proper insulin signalling is reinstated that contributes to decreased metabolic failure and conceivably reduced APP processing products in DS [84, 97, 100, 101].

As noted above, AMPK signalling is a major inducer of autophagy associated with the reduction of energy metabolism [59]. The loss of sensitivity of AMPK activation to cellular stress impairs metabolic regulation, increases oxidative stress and reduces autophagic clearance. Recent studies confirmed that the responsiveness of AMPK to different insults is clearly suppressed in aged tissues during mTOR overactivation. In line with this proposed scenario, AMPK signal is dampened in Ts65Dn mice. Intriguingly, the inhibition of mTOR, by InRapa treatment, lead to increased phosphorylation of AMPK on its activatory residue rescuing signalling induction.
Noteworthy, previous reports demonstrated that AMPK activation is able to induce autophagy by also phosphorylating Ulk1, beyond inhibiting mTOR signalling [102].

The sequence of pathological mechanisms of DS neurodegeneration in Ts65Dn mice include aberrant tau phosphorylation, associated with the increased activation state of different tau kinases. Among these, DYRK1A and RCAN1 encoded on HSA21, and GSK3 $\beta$ and CDK5 seem to have a prominent role in tau hyper-phosphorylation occurring in the brain of $\mathrm{AD}$ and DS subjects [72].

Substantial evidence supports the critical role of mTOR in tau-related pathological progress in DS. A number of studies sustain that the activation of mTOR signalling promotes tau hyper-phosphorylation, while its inhibition prevents this phenomenon [27-29, 32, 95]. In particular, the mechanisms by which altered mTOR signalling lead to tau hyper-phosphorylation include the aberrant regulation of tau kinases and the reduction of autophagy. Ts65Dn mice after InRapa treatment demonstrate a robust and significant reduction of tau phosphorylation in the hippocampus, both total and CA3 region-specific. The reduction is associated with significantly decreased expression of RCAN1 and with a trend of decreased DYRK1A levels. No alteration is shown for CDK5 in Ts65Dn prior or after the treatment, while an opposite trend is reported for GSK3 $\beta$, as previously reported also in human studies [13]. Despite the reduction of tau kinases, lowered levels of hyperphosphorylated tau cannot be observed after InRapa administration without the increase of autophagosome formation, which play a key role in the clearence of intracellular toxic tau aggregates. These results suggest that rapamycin is able to reduce the degree of tau phosphorylation by modulating the expression of certain tau kinases, and to improve hyperphosphorylated tau degradation through the induction of autophagy [103-105].

A further intriguing outcome observed after InRapa treatment is represented by the reduction of protein oxidative damage in Ts65Dn mice. Increased oxidative stress is a characteristic feature of DS neuropathology in humans and mice $[3,74,106]$. Data collected in DS human brain indicated that oxidative damage targeted specific components of the proteostasis network, resulting in dysfunctional activation of autophagy and the ubiquitin proteasome system $[7,9,70]$. Previous studies by our laboratory demonstrated that the chronic increase of OS in Ts65Dn mice with aging, in parallel with reduced autophagy, leads to the accumulation of total protein-bound HNE and protein nitration levels [22]. Therefore, a vicious cycle that involves the prolonged failure of protein degradation systems and the chronic build-up of oxidized protein may exist in DS. The rescue of mTOR activity, by InRapa treatment, likely induces the autophagy-driven degradation of oxidized proteins as demonstrated through the decrease of total protein-bound HNE levels and total 
protein nitration. In addition, studies on DS human brain reported that the accumulation of oxidative damage is coupled with increased levels of poly-ubiquitinylated proteins, prior to and after the development of AD [10]. Despite, Ts65Dn did not recapitulate the same profile of protein poly-ubiquitinylation observed in humans an increase in poly-Lys63 ubiquitinylation levels were observed. These data suggest that impairment of the proteasome system in Ts65Dn mice is less pronounced compared with humans, supporting the concept that the failure of protein degradation is related to the impairment of the autophagy pathway rather than to the impairment of the UPS. Noteworthy, InRapa treatment was able to reduce the poly-ubiquitinylation of Lys63 residues supporting the restoration of autophagy and implying a certain degree the crosstalk between mTOR and UPS.

\section{Conclusions}

Overall, we demonstrated that rapamycin, administered for 3 months by intranasal route, led to improved cognition in DS mice with no effects at peripheral organs. The favorable outcomes of rapamycin treatment seem to rely on its ability to rescue molecular pathways associated with aberrant mTOR phosphorylation, whose alteration accelerate the age-related neurodegenerative process and increase the risk of $\mathrm{AD}$ development in DS. Therefore, InRapa treatment represents an attractive therapeutic strategy to reduce the early development of neuropathology in DS population and delay the onset of AD. At final, this therapeutic strategy may be also translated to different neuronal disorders that share, as a common pathological mechanism, the alteration of mTOR/autophagy axis.

\section{Additional files}

Additional file 1: List of antibodies used for WB and IF analysis. For each antibody employed in the study is reported the brand, the catalogue number and the dilution employed in the study. (PPTX $146 \mathrm{~kb}$ )

Additional file 2: Bar graph reporting mice distance traveled during RAM test. The distance travelled was measured for $10 \mathrm{~min}$ at the end of the test days in all experimental groups, no differences were found between the groups. (PPTX $2553 \mathrm{~kb}$ )

Additional file 3: Pilot studies to assess InRapa therapeutic dose. Mice were treated by InRapa daily for 1 week after which brain regions were collected and analyzed. Phosphorylation levels of mTOR in both hippocampus and cortex are reported for each of the dose tested, $0.01 \mu \mathrm{g} / \mu \mathrm{l}$ ( $0.1 \mu \mathrm{g} /$ mouse), $0.05 \mu \mathrm{g} / \mu \mathrm{l}(0.5 \mu \mathrm{g} /$ mouse), $0.1 \mu \mathrm{g} / \mu \mathrm{l}(1 \mu \mathrm{g} / \mathrm{mouse})$ and $0.2 \mu \mathrm{g} / \mathrm{\mu l}(2 \mu \mathrm{g} / \mathrm{mouse})$. Each value is the mean of 6 replicate \pm SEM. Our data demonstrate that the InRapa dosage of $0.1 \mu \mathrm{g} / \mu \mathrm{l}(1 \mu \mathrm{g} /$ mouse) is able to inhibit mTOR phosphorylation when compared to vehicle. (PPTX $1203 \mathrm{~kb}$ )

Additional file 4: Table reporting 2-way ANOVA data analysis. For 2-way ANOVA analysis only proteins showing changes before and after the InRapa treatment have been taken under consideration. (PPTX $844 \mathrm{~kb}$ )

Additional file 5: Rapamycin distribution by UPLC-MS. Chromatograms of rapamycin in plasma (A) and brain (B) from animals treated by single I.P. injection of $50 \mu \mathrm{g} / \mathrm{mouse}(2,5 \mathrm{mg} / \mathrm{kg} / \mathrm{mouse}) 4 \mathrm{~h}$ before sacrifice. Chromatograms of rapamycin in plasma (C) and brain (D) from animals treated by single InRapa administration of $1 \mu \mathrm{g} /$ mouse $(0.05 \mathrm{mg} / \mathrm{Kg} /$ mouse) $4 \mathrm{~h}$ before sacrifice. (PPTX $50 \mathrm{~kb}$ )

Additional file 6: Western blot analysis of mTOR and p7056K phosphorylation in liver and heart tissue after InRapa treatment. Graph bars are reported as percentage in respect to euploid vehicle group, which is set as $100 \%$. Data Show no significant alteration in Ts65Dn undergoing rapamycin (black bar) or vehicle (checquered bars) after intranasal delivery supporting no effects of InRapa treatment at peripheral level. (PPTX $72 \mathrm{~kb}$ )

Additional file 7: Immunofluorescence staining of Dentate gyrus in Eu and Ts65Dn mice. Representative immunofluorescent images showing (A) p-mTOR at serine 2448, (B) at Ser416 and (C) APP/Ab levels in the dentate gyrus region of the hippocampus from euploid mice treated with Veh and InRapa (A.1-4), and Ts65Dn mice treated with Veh and InRapa (A.5-8). DAPI (blue) was used to identify cell nuclei. Scale bar represent $20 \mu \mathrm{m}$. On the right of each panel a graph of the quantification of fluorescence signal is reported. (PPTX $16410 \mathrm{~kb}$ )

\section{Abbreviations}

3-NT: 3-Nitrotyrosine; AD: Alzheimer's Disease; AMPK: AMP-activated protein kinase; APP: Amyloid Precursor Protein; Atg: Autophagy related proteins; $A \beta$ : Amyloid- $\beta$; BACE1: Beta-secretase 1; CDK5: cyclin dependent kinase 5; CNS: Central Nervous System; Ct: threshold cycle; DI: Discrimination Index; DS: Down Syndrome; DYRK1A: Dual specificity tyrosine-phosphorylationregulated kinase 1A; Eu: Euploid; GAPDH: Glyceraldehyde-3-Phosphate Dehydrogenase; GSK3ß: glycogen synthase kinase 3 isoforms $\beta$; HNE: 4Hydroxynonenal; Hsa21: human chromosome 21; InRapa: Intranasal Rapamycin; IRS-1: Insulin Receptor Substrate-1; LC3: Microtubule-associated protein 1A/1B-light chain 3; mTOR: mammalian Target Of Rapamycin; NFT: Neurofibrillary Tangles; NOR: Novel Object Recognition; OS: Oxidative Stress; P70S6K: ribosomal p70S6 kinase; Pdebrd1: Recessive Retinal Degeneration 1 Mutation; PI: preference Index; PI3K: Phosphoinositide-3Kinase; PQC: Protein Quality Control; PTEN: phosphatase and tensin homolog; RAM: Radial Arm Maze; Rapa: Rapamycin; RCAN1: Regulator of Calcineurin 1; RME: reference memory errors; RNS: Reactive Nitrogen Species; ROS: Reactive Oxygen Species; RT-PCR: Real time Polymerase Chain Reaction;

Tg: Transgenic; UPLC: Ultra-performance/pressure Liquid Chromatography analysis; UPS: Ubiquitin Proteasome System; Veh: Vehicle; WME: working memory errors

\section{Acknowledgements}

Not applicable.

\section{Funding}

This work was supported by the Ministry of Instruction, Universities and Research (MIUR) under the SIR program $n^{\circ}$ RBSI144MT to FDD, Jerome Lejeune Foundation with the grant \# PERLUIGI/1484-PM2016A to MP and Fondi di Ateneo Progetti Grandi \# RG1 16154C9214D1A from Sapienza University of Rome to FDD.

\section{Availability of data and materials}

All data generated or analysed during this study are included in this published article [and its supplementary information files].

\section{Authors' contributions}

FDD and MP were involved in designing the study and the experimental procedure, and in the preparation of the manuscript; $A T, C L, E B, A A$ and $I Z$ were involved in animal treatment and in performing the experimental procedures; LM was involved in UPLC/MS analysis; CB was involved in manuscript preparation and correction; DAB was involved in study design and manuscript revising. All authors read and approved the final manuscript.

\section{Authors' information}

Not applicable

\section{Ethics approval}

All the experiments were performed in strict compliance with the Italian National Laws (DL 116/92), the European Communities Council Directives (86/609/EEC). Experimental protocol was approved by Italian Ministry of 
Health authorization $n^{\circ} 1183 / 2016-P R$. All efforts were made to minimize the number of animals used in the study and their suffering.

\section{Consent for publication}

Not applicable.

\section{Competing interests}

The authors declare that they have no competing interests.

\section{Author details}

${ }^{1}$ Department of Biochemical Sciences, Sapienza University of Rome, P.le Aldo Moro 5, 00185 Rome, Italy. ${ }^{2}$ Universidad Autònoma de Chile, Instituto de Ciencias Biomédicas, Facultad de alud, Avenida Pedro de Valdivia 425, Providencia, Santiago, Chile. ${ }^{3}$ Department of Chemistry and Sanders-Brown Center on Aging, University of Kentucky, Lexington, KY 40506-0055, USA.

Received: 16 July 2018 Accepted: 11 October 2018 Published online: 06 November 2018

\section{References}

1. Wiseman FK, Al-Janabi T, Hardy J, Karmiloff-Smith A, Nizetic D, Tybulewicz VL, Fisher EM, Strydom A. A genetic cause of Alzheimer disease: mechanistic insights from Down syndrome. Nat Rev Neurosci. 2015;16:564-74.

2. Head E, Powell D, Gold BT, Schmitt FA. Alzheimer's disease in Down syndrome. Eur J Neurodegener Dis. 2012;1:353-64.

3. Perluigi M, Di Domenico F, Buttterfield DA. Unraveling the complexity of neurodegeneration in brains of subjects with Down syndrome: insights from proteomics. Proteomics Clin Appl. 2014;8:73-85.

4. Cheon MS, Dierssen M, Kim SH, Lubec G. Protein expression of BACE1, BACE2 and APP in Down syndrome brains. Amino Acids. 2008;35:339-43.

5. Jiang Y, Mullaney KA, Peterhoff CM, Che S, Schmidt SD, Boyer-Boiteau A, Ginsberg SD, Cataldo AM, Mathews PM, Nixon RA. Alzheimer's-related endosome dysfunction in Down syndrome is Abeta-independent but requires APP and is reversed by BACE-1 inhibition. Proc Natl Acad Sci U S A. 2010;107:1630-5.

6. Salehi A, Delcroix JD, Belichenko PV, Zhan K, Wu C, Valletta JS, TakimotoKimura R, Kleschevnikov AM, Sambamurti K, Chung PP, et al. Increased app expression in a mouse model of Down's syndrome disrupts NGF transport and causes cholinergic neuron degeneration. Neuron. 2006;51:29-42.

7. Di Domenico F, Coccia R, Cocciolo A, Murphy MP, Cenini G, Head E, Butterfield DA, Giorgi A, Schinina ME, Mancuso C, et al. Impairment of proteostasis network in Down syndrome prior to the development of Alzheimer's disease neuropathology: redox proteomics analysis of human brain. Biochim Biophys Acta. 1832;2013:1249-59.

8. Perluigi M, Di Domenico F, Butterfield DA. mTOR signaling in aging and neurodegeneration: at the crossroad between metabolism dysfunction and impairment of autophagy. Neurobiol Dis. 2015;84:39-49.

9. Di Domenico F, Pupo G, Tramutola A, Giorgi A, Schinina ME, Coccia R, Head E, Butterfield DA, Perluigi M. Redox proteomics analysis of HNE-modified proteins in Down syndrome brain: clues for understanding the development of Alzheimer disease. Free Radic Biol Med. 2014;71:270-80

10. Tramutola A, Di Domenico F, Barone E, Arena A, Giorgi A, di Francesco L, Schinina ME, Coccia R, Head E, Butterfield DA, Perluigi M. Polyubiquitinylation profile in Down syndrome brain before and after the development of Alzheimer neuropathology. Antioxid Redox Signal. 2017;26:280-98.

11. Tramutola A, Triani F, Di Domenico F, Barone E, Cai J, Klein JB, Perluigi M, Butterfield DA. Poly-ubiquitin profile in Alzheimer disease brain. Neurobiol Dis. 2018;118:129-41.

12. O' Neill C. PI3-kinase/Akt/mTOR signaling: impaired on/off switches in aging, cognitive decline and Alzheimer's disease. Exp Gerontol. 2013;48:647-53.

13. Perluigi M, Pupo G, Tramutola A, Cini C, Coccia R, Barone E, Head E, Butterfield DA, Di Domenico F: Neuropathological role of PI3K/Akt/mTOR axis in Down syndrome brain. Biochim Biophys Acta 2014, 1842:1144-1153.

14. Hoeffer CA, Klann E. mTOR signaling: at the crossroads of plasticity, memory and disease. Trends Neurosci. 2010;33:67-75.

15. Laplante M, Sabatini DM. mTOR Signaling. Cold Spring Harb Perspect Biol. 2012:4:1-3.

16. Ma T, Hoeffer CA, Capetillo-Zarate E, Yu F, Wong H, Lin MT, Tampellini D, Klann E, Blitzer RD, Gouras GK. Dysregulation of the mTOR pathway mediates impairment of synaptic plasticity in a mouse model of Alzheimer's disease. PLoS One. 2010;5:1-10.
17. Cai Z, Chen G, He W, Xiao M, Yan LJ. Activation of mTOR: a culprit of Alzheimer's disease? Neuropsychiatr Dis Treat. 2015;11:1015-30.

18. Oddo S. The role of mTOR signaling in Alzheimer disease. Front Biosci. 2012; 4:941-52.

19. Spilman P, Podlutskaya N, Hart MJ, Debnath J, Gorostiza O, Bredesen D, Richardson A, Strong R, Galvan V. Inhibition of mTOR by rapamycin abolishes cognitive deficits and reduces amyloid-beta levels in a mouse model of Alzheimer's disease. PLoS One. 2010;5:e9979.

20. Tramutola A, Lanzillotta C, Di Domenico F. Targeting mTOR to reduce Alzheimer-related cognitive decline: from current hits to future therapies. Expert Rev Neurother. 2017;17:33-45.

21. lyer AM, van Scheppingen J, Milenkovic I, Anink JJ, Adle-Biassette H, Kovacs GG, Aronica E. mTOR Hyperactivation in Down syndrome hippocampus appears early during development. J Neuropathol Exp Neurol. 2014;73:671-83.

22. Tramutola A, Lanzillotta C, Arena A, Barone E, Perluigi M, Di Domenico F. Increased mammalian target of rapamycin signaling contributes to the accumulation of protein oxidative damage in a mouse model of Down's syndrome. Neurodegener Dis. 2016;16:62-8.

23. Cai Z, Zhao B, Li K, Zhang L, Li C, Quazi SH, Tan Y. Mammalian target of rapamycin: a valid therapeutic target through the autophagy pathway for Alzheimer's disease? J Neurosci Res. 2012;90:1105-18.

24. Franco R, Martinez-Pinilla E, Navarro G, Zamarbide M. Potential of GPCRs to modulate MAPK and mTOR pathways in Alzheimer's disease. Prog Neurobiol. 2017;149-150:21-38.

25. Chong ZZ, Shang YC, Zhang L, Wang S, Maiese K. Mammalian target of rapamycin: hitting the bull's-eye for neurological disorders. Oxidative Med Cell Longev. 2010;3:374-91.

26. Richardson A, Galvan V, Lin AL, Oddo S. How longevity research can lead to therapies for Alzheimer's disease: the rapamycin story. Exp Gerontol. 2015; 68:51-8.

27. Siman $R$, Cocca $R$, Dong $Y$. The mTOR inhibitor rapamycin mitigates Perforant pathway neurodegeneration and synapse loss in a mouse model of early-stage Alzheimer-type Tauopathy. PLoS One. 2015;10:e0142340.

28. Tang Z, Bereczki E, Zhang H, Wang S, Li C, Ji X, Branca RM, Lehtio J, Guan Z, Filipcik $P$, et al. Mammalian target of rapamycin (mTor) mediates tau protein dyshomeostasis: implication for Alzheimer disease. J Biol Chem. 2013;288:15556-70.

29. Caccamo A, Majumder S, Richardson A, Strong R, Oddo S. Molecular interplay between mammalian target of rapamycin (mTOR), amyloid-beta, and tau: effects on cognitive impairments. J Biol Chem. 2010;285:13107-20.

30. Caccamo A, Maldonado MA, Majumder S, Medina DX, Holbein W, Magri A, Oddo S. Naturally secreted amyloid-beta increases mammalian target of rapamycin (mTOR) activity via a PRAS40-mediated mechanism. J Biol Chem. 2011;286:8924-32

31. Majumder S, Richardson A, Strong R, Oddo S. Inducing autophagy by rapamycin before, but not after, the formation of plaques and tangles ameliorates cognitive deficits. PLoS One. 2011;6:e25416.

32. Oddo S, Vasilevko V, Caccamo A, Kitazawa M, Cribbs DH, LaFerla FM. Reduction of soluble Abeta and tau, but not soluble Abeta alone, ameliorates cognitive decline in transgenic mice with plaques and tangles. J Biol Chem. 2006;281:39413-23.

33. Reinholdt LG, Ding Y, Gilbert GJ, Czechanski A, Solzak JP, Roper RJ, Johnson MT, Donahue LR, Lutz C, Davisson MT. Molecular characterization of the translocation breakpoints in the Down syndrome mouse model Ts65Dn. Mamm Genome. 2011;22:685-91.

34. Ennaceur A. One-trial object recognition in rats and mice: methodological and theoretical issues. Behav Brain Res. 2010;215:244-54.

35. Antunes $M$, Biala $G$. The novel object recognition memory: neurobiology, test procedure, and its modifications. Cogn Process. 2012;13:93-110.

36. Vorhees CV, Williams MT. Assessing spatial learning and memory in rodents. ILAR J. 2014:55:310-32

37. Livak KJ, Schmittgen TD. Analysis of relative gene expression data using real-time quantitative PCR and the 2(T)(-Delta Delta C) method. Methods. 2001;25:402-8.

38. Sarbassov DD, Ali SM, Kim DH, Guertin DA, Latek RR, Erdjument-Bromage $H$, Tempst $P$, Sabatini DM. Rictor, a novel binding partner of mTOR, defines a rapamycin-insensitive and raptor-independent pathway that regulates the cytoskeleton. Curr Biol. 2004;14:1296-302.

39. Jung $\mathrm{CH}$, Ro SH, Cao J, Otto NM, Kim DH. mTOR regulation of autophagy. FEBS Lett. 2010;584:1287-95.

40. Orr ME, Oddo S. Autophagic/lysosomal dysfunction in Alzheimer's disease. Alzheimers Res Ther. 2013;5:53. 
41. Nixon RA. Autophagy, amyloidogenesis and Alzheimer disease. J Cell Sci. 2007;120:4081-91.

42. Nixon RA, Yang DS. Autophagy failure in Alzheimer's disease--locating the primary defect. Neurobiol Dis. 2011;43:38-45.

43. Klionsky DJ, Abdelmohsen K, Abe A, Abedin MJ, Abeliovich H, Acevedo Arozena A, Adachi H, Adams CM, Adams PD, Adeli K, et al. Guidelines for the use and interpretation of assays for monitoring autophagy (3rd edition). Autophagy. 2016;12:1-222.

44. Webb RL, Murphy MP. beta-Secretases, Alzheimer's Disease, and Down Syndrome. Curr Gerontol Geriatr Res. 2012;2012:362839.

45. Mori C, Spooner ET, Wisniewsk KE, Wisniewski TM, Yamaguch H, Saido TC, Tolan DR, Selkoe DJ, Lemere CA. Intraneuronal Abeta42 accumulation in Down syndrome brain. Amyloid. 2002;9:88-102.

46. Seo H, Isacson O, Abnormal APP. Cholinergic and cognitive function in Ts65Dn Down's model mice. Exp Neurol. 2005;193:469-80.

47. Lomoio S, Scherini E, Necchi D. Beta-amyloid overload does not directly correlate with SAPK/JNK activation and tau protein phosphorylation in the cerebellar cortex of Ts65Dn mice. Brain Res. 2009;1297:198-206.

48. Hunter $\mathrm{CL}$, Bimonte-Nelson HA, Nelson M, Eckman CB, Granholm AC. Behavioral and neurobiological markers of Alzheimer's disease in Ts65Dn mice: effects of estrogen. Neurobiol Aging. 2004;25:873-84.

49. Yu T, Li ZY, Jia ZP, Clapcote SJ, Liu CH, Li SM, Asrar S, Pao A, Chen RQ, Fan $\mathrm{N}$, et al. A mouse model of Down syndrome trisomic for all human chromosome 21 syntenic regions. Hum Mol Genet. 2010;19:2780-91.

50. Choi JH, Berger JD, Mazzella MJ, Morales-Corraliza J, Cataldo AM, Nixon RA, Ginsberg SD, Levy E, Mathews PM. Age-dependent dysregulation of brain amyloid precursor protein in the Ts65Dn Down syndrome mouse model. J Neurochem. 2009;110:1818-27.

51. Liu F, Liang Z, Wegiel J, Hwang YW, lqbal K, Grundke-lqbal I, Ramakrishna N, Gong CX. Overexpression of Dyrk1A contributes to neurofibrillary degeneration in Down syndrome. FASEB J. 2008;22:3224-33.

52. Ryoo SR, Jeong HK, Radnaabazar C, Yoo JJ, Cho HJ, Lee HW, Kim IS, Cheon YH, Ahn YS, Chung SH, Song WJ. DYRK1A-mediated hyperphosphorylation of tau. A functional link between Down syndrome and Alzheimer disease. J Biol Chem. 2007;282:34850-7.

53. Jung MS, Park JH, Ryu YS, Choi SH, Yoon SH, Kwen MY, Oh JY, Song WJ, Chung SH. Regulation of RCAN1 protein activity by Dyrk1A proteinmediated phosphorylation. J Biol Chem. 2011;286:40401-12.

54. Ermak G, Harris CD, Battocchio D, Davies KJ. RCAN1 (DSCR1 or Adapt78) stimulates expression of GSK-3beta. FEBS J. 2006;273:2100-9.

55. Ermak G, Sojitra S, Yin F, Cadenas E, Cuervo AM, Davies KJ. Chronic expression of RCAN1-1L protein induces mitochondrial autophagy and metabolic shift from oxidative phosphorylation to glycolysis in neuronal cells. J Biol Chem. 2012;287:14088-98.

56. Sheppard O, Plattner F, Rubin A, Slender A, Linehan JM, Brandner S, Tybulewicz $\mathrm{V}$, Fisher EM, Wiseman FK. Altered regulation of tau phosphorylation in a mouse model of Down syndrome aging. Neurobiol Aging. 2012;33:828 e831-44.

57. Swatton JE, Sellers LA, Faull RLM, Holland A, Iritani S, Bahn S. Increased MAP kinase activity in Alzheimer's and Down syndrome but not in schizophrenia human brain. Eur J Neurosci. 2004;19:2711-9.

58. Pollonini G, Gao V, Rabe A, Palminiello S, Albertini G, Alberini CM. Abnormal expression of synaptic proteins and neurotrophin-3 in the Down syndrome mouse model Ts65Dn. Neuroscience. 2008;156:99-106.

59. Xu J, Ji J, Yan XH. Cross-talk between AMPK and mTOR in regulating energy balance. Crit Rev Food Sci. 2012;52:373-81.

60. Chakrabarti L, Galdzicki Z, Haydar TF. Defects in embryonic neurogenesis and initial synapse formation in the forebrain of the Ts65Dn mouse model of Down syndrome. J Neurosci. 2007;27:11483-95.

61. Lorenzi HA, Reeves RH. Hippocampal hypocellularity in the Ts65Dn mouse originates early in development. Brain Res. 2006;1104:153-9.

62. Contestabile A, Fila T, Ceccarelli C, Bonasoni P, Bonapace L, Santini D, Bartesaghi R, Ciani E. Cell cycle alteration and decreased cell proliferation in the hippocampal dentate gyrus and in the neocortical germinal matrix of fetuses with Down syndrome and in Ts65Dn mice. Hippocampus. 2007;17:665-78.

63. Contestabile A, Fila T, Bartesaghi R, Ciani E. Cell cycle elongation impairs proliferation of cerebellar granule cell precursors in the Ts65Dn mouse, an animal model for Down syndrome. Brain Pathol. 2009;19:224-37.

64. Guidi S, Bonasoni P, Ceccarelli C, Santini D, Gualtieri F, Ciani E, Bartesaghi R. Neurogenesis impairment and increased cell death reduce total neuron number in the hippocampal region of fetuses with Down syndrome. Brain Pathol. 2008;18:180-97.
65. Insausti AM, Megias M, Crespo D, Cruz-Orive LM, Dierssen M, Vallina IF, Insausti R, Florez J. Hippocampal volume and neuronal number in Ts65Dn mice: a murine model of Down syndrome. Neurosci Lett. 1998;253:175-8.

66. Kleschevnikov AM, Belichenko PV, Villar AJ, Epstein CJ, Malenka RC, Mobley WC. Hippocampal long-term potentiation suppressed by increased inhibition in the Ts65Dn mouse, a genetic model of Down syndrome. J Neurosci. 2004;24:8153-60

67. Guidi S, Stagni F, Bianchi P, Ciani E, Giacomini A, De Franceschi M, Moldrich R, Kurniawan N, Mardon K, Giuliani A, et al. Prenatal pharmacotherapy rescues brain development in a Down's syndrome mouse model. Brain. 2014;137:380-401.

68. Giacomini A, Stagni F, Trazzi S, Guidi S, Emili M, Brigham E, Ciani E, Bartesaghi R. Inhibition of APP gamma-secretase restores sonic hedgehog signaling and neurogenesis in the Ts65Dn mouse model of Down syndrome. Neurobiol Dis. 2015;82:385-96.

69. Stagni F, Raspanti A, Giacomini A, Guidi S, Emili M, Ciani E, Giuliani A, Bighinati A, Calza L, Magistretti J, Bartesaghi R. Long-term effect of neonatal inhibition of APP gamma-secretase on hippocampal development in the Ts65Dn mouse model of Down syndrome. Neurobiol Dis. 2017;103:11-23.

70. Di Domenico F, Pupo G, Mancuso C, Barone E, Paolini F, Arena A, Blarzino C, Schmitt FA, Head E, Butterfield DA, Perluigi M. Bach1 overexpression in Down syndrome correlates with the alteration of the HO-1/BVR-a system: insights for transition to Alzheimer's disease. J Alzheimers Dis. 2015;44:1107-20.

71. Lanzillotta C, Tramutola A, Meier S, Schmitt F, Barone E, Perluigi M, Di Domenico F, Abisambra JF. Early and selective activation and subsequent alterations to the unfolded protein response in Down syndrome mouse models. J Alzheimers Dis. 2018;62:347-59.

72. Di Domenico F, Tramutola A, Foppoli C, Head E, Perluigi M, Butterfield DA. mTOR in Down syndrome: role in ass and tau neuropathology and transition to Alzheimer disease-like dementia. Free Radic Biol Med. 2018;114:94-101.

73. Korolchuk VI, Menzies FM, Rubinsztein DC. Mechanisms of cross-talk between the ubiquitin-proteasome and autophagy-lysosome systems. FEBS Lett. 2010;584:1393-8.

74. Butterfield DA, Di Domenico F, Swomley AM, Head E, Perluigi M. Redox proteomics analysis to decipher the neurobiology of Alzheimer-like neurodegeneration: overlaps in Down's syndrome and Alzheimer's disease brain. Biochem J. 2014:463:177-89.

75. Head E, Lott IT, Wilcock DM, Lemere CA. Aging in Down syndrome and the development of Alzheimer's disease neuropathology. Curr Alzheimer Res. 2016;13:18-29.

76. Lemere CA, Blusztajn JK, Yamaguchi H, Wisniewski T, Saido TC, Selkoe DJ. Sequence of deposition of heterogeneous amyloid beta-peptides and APO E in Down syndrome: implications for initial events in amyloid plaque formation. Neurobiol Dis. 1996;3:16-32.

77. Troca-Marin JA, Alves-Sampaio A, Montesinos ML. Deregulated mTORmediated translation in intellectual disability. Prog Neurobiol. 2012;96:268-82.

78. Andrade-Talavera Y, Benito I, Casanas JJ, Rodriguez-Moreno A, Montesinos ML. Rapamycin restores BDNF-LTP and the persistence of long-term memory in a model of Down's syndrome. Neurobiol Dis. 2015;82:516-25.

79. Caccamo A, Majumder S, Deng JJ, Bai Y, Thornton FB, Oddo S. Rapamycin rescues TDP-43 mislocalization and the associated low molecular mass neurofilament instability. J Biol Chem. 2009;284:27416-24.

80. Lin AL, Zheng W, Halloran JJ, Burbank RR, Hussong SA, Hart MJ, Javors M, Shih YY, Muir E, Solano Fonseca $\mathrm{R}$, et al. Chronic rapamycin restores brain vascular integrity and function through NO synthase activation and improves memory in symptomatic mice modeling Alzheimer's disease. J Cereb Blood Flow Metab. 2013;33:1412-21.

81. Ramirez AE, Pacheco CR, Aguayo LG, Opazo CM. Rapamycin protects against Abeta-induced synaptotoxicity by increasing presynaptic activity in hippocampal neurons. Biochim Biophys Acta. 1842;2014:1495-501.

82. Lochhead JJ, Thorne RG. Intranasal delivery of biologics to the central nervous system. Adv Drug Deliv Rev. 2012;64:614-28.

83. Barone E, Tramutola A, Triani F, Calcagnini S, Di Domenico F, Ripoli C, Gaetani S, Grassi C, Butterfield DA, Cassano T, Perluigi M. Biliverdin Reductase-A Mediates the beneficial effects of intranasal insulin in Alzheimer disease. Mol Neurobiol. 2018; https://doi.org/10.1007/s12035-018-1231-5.

84. Chen Y, Zhao Y, Dai CL, Liang Z, Run X, lqbal K, Liu F, Gong CX. Intranasal insulin restores insulin signaling, increases synaptic proteins, and reduces Abeta level and microglia activation in the brains of 3xTg-AD mice. Exp Neurol. 2014;261:610-9.

85. Freiherr J, Hallschmid M, Frey WH, Brunner YF, Chapman CD, Holscher C, Craft S, De Felice FG, Benedict C. Intranasal insulin as a treatment for 
Alzheimer's disease: a review of basic research and clinical evidence. Cns Drugs. 2013;27:505-14.

86. Ram G, Chinen J. Infections and immunodeficiency in Down syndrome. Clin Exp Immunol. 2011;164:9-16.

87. Carsetti R, Valentini D, Marcellini V, Scarsella M, Marasco E, Giustini F, Bartuli A, Villani A, Ugazio AG. Reduced numbers of switched memory B cells with high terminal differentiation potential in Down syndrome. Eur J Immunol. 2015:45:903-14.

88. Kusters MA, Verstegen RH, Gemen EF, de Vries E. Intrinsic defect of the immune system in children with Down syndrome: a review. Clin Exp Immunol. 2009;156:189-93.

89. Cuadrado E, Barrena MJ. Immune dysfunction in Down's syndrome: primary immune deficiency or early senescence of the immune system? Clin Immunol Immunopathol. 1996;78:209-14.

90. Butterfield DA, Galvan V, Lange MB, Tang H, Sowell RA, Spilman P, Fombonne J, Gorostiza O, Zhang J, Sultana R, Bredesen DE. In vivo oxidative stress in brain of Alzheimer disease transgenic mice: requirement for methionine 35 in amyloid beta-peptide of APP. Free Radic Biol Med. 2010;48:136-44.

91. Zhao J, Garcia GA, Goldberg AL. Control of proteasomal proteolysis by mTOR. Nature. 2016;529:E1-2.

92. Laplante M, Sabatini DM. Regulation of mTORC1 and its impact on gene expression at a glance. J Cell Sci. 2013;126:1713-9.

93. Wolvetang EW, Bradfield OM, Tymms M, Zavarsek S, Hatzistavrou T, Kola I, Hertzog PJ. The chromosome 21 transcription factor ETS2 transactivates the beta-APP promoter: implications for Down syndrome. Biochim Biophys Acta. 2003;1628:105-10.

94. Li M, Zhang Z, Hill DL, Wang H, Zhang RW. Curcumin, a dietary component, has anticancer, chemosensitization, and radiosensitization effects by downregulating the MDM2 oncogene through the PI3K/mTOR/ETS2 pathway. Cancer Res. 2007;67:1988-96.

95. Caccamo A, Magri A, Medina DX, Wisely EV, Lopez-Aranda MF, Silva AJ, Oddo S. mTOR regulates tau phosphorylation and degradation: implications for Alzheimer's disease and other tauopathies. Aging Cell. 2013;12:370-80.

96. Barone E, Di Domenico F, Cassano T, Arena A, Tramutola A, Lavecchia MA, Coccia R, Butterfield DA, Perluigi M. Impairment of biliverdin reductase-a promotes brain insulin resistance in Alzheimer disease: a new paradigm. Free Radic Biol Med. 2016;91:127-42.

97. Bedse G, Di Domenico F, Serviddio G, Cassano T. Aberrant insulin signaling in Alzheimer's disease: current knowledge. Front Neurosci. 2015;9:204.

98. Haruta T, Uno T, Kawahara J, Takano A, Egawa K, Sharma PM, Olefsky JM, Kobayashi M. A rapamycin-sensitive pathway down-regulates insulin signaling via phosphorylation and proteasomal degradation of insulin receptor substrate-1. Mol Endocrinol. 2000;14:783-94.

99. Butterfield DA, Di Domenico F, Barone E. Elevated risk of type 2 diabetes for development of Alzheimer disease: a key role for oxidative stress in brain. Biochim Biophys Acta. 1842;2014:1693-706.

100. Mao YF, Guo Z, Zheng T, Jiang Y, Yan Y, Yin X, Chen Y, Zhang B. Intranasal insulin alleviates cognitive deficits and amyloid pathology in young adult APPswe/PS1dE9 mice. Aging Cell. 2016;15:893-902.

101. Solano DC, Sironi M, Bonfini C, Solerte SB, Govoni S, Racchi M. Insulin regulates soluble amyloid precursor protein release via phosphatidyl inositol 3 kinase-dependent pathway. FASEB J. 2000;14:1015-22.

102. Kim J, Kundu M, Viollet B, Guan KL. AMPK and mTOR regulate autophagy through direct phosphorylation of Ulk1. Nat Cell Biol. 2011;13:132-41.

103. Cardenas AM, Ardiles AO, Barraza N, Baez-Matus X, Caviedes P. Role of tau protein in neuronal damage in Alzheimer's disease and Down syndrome. Arch Med Res. 2012;43:645-54.

104. Lee MJ, Lee JH, Rubinsztein DC. Tau degradation: the ubiquitin-proteasome system versus the autophagy-lysosome system. Prog Neurobiol. 2013;105: 49-59.

105. Wang Y, Martinez-Vicente M, Kruger U, Kaushik S, Wong E, Mandelkow EM Cuervo AM, Mandelkow E. Tau fragmentation, aggregation and clearance: the dual role of lysosomal processing. Hum Mol Genet. 2009;18:4153-70.

106. Barone E, Head E, Butterfield DA, Perluigi M. HNE-modified proteins in Down syndrome: involvement in development of Alzheimer disease neuropathology. Free Radic Biol Med. 2017;111:262-9.

Ready to submit your research? Choose BMC and benefit from:

- fast, convenient online submission

- thorough peer review by experienced researchers in your field

- rapid publication on acceptance

- support for research data, including large and complex data types

- gold Open Access which fosters wider collaboration and increased citations

- maximum visibility for your research: over $100 \mathrm{M}$ website views per year

At BMC, research is always in progress.

Learn more biomedcentral.com/submissions 